\title{
Site-specific ubiquitination of the E3 ligase HOIP regulates cell death and immune signaling
}

Lilian M. Fennell ${ }^{1}$, Luiza Deszcz ${ }^{1}$, Alexander Schleiffer ${ }^{1,2}$, Karl Mechtler ${ }^{1,2}$, Anoop Kavirayani ${ }^{3}$, Fumiyo Ikeda ${ }^{1,4^{*}}$

${ }^{1}$ IMBA - Institute of Molecular Biotechnology of the Austrian Academy of Science, Vienna Biocenter (VBC), Vienna, Austria

${ }^{2}$ Research Institute of Molecular Pathology (IMP), Vienna Biocenter (VBC), Vienna, Austria

${ }^{3}$ Vienna Biocenter Core Facilities (VBCF), Vienna Biocenter (VBC), Vienna, Austria

${ }^{4}$ Medical Institute of Bioregulation (MIB), Kyushu University, Fukuoka, Japan

*Correspondence: Fumiyo Ikeda, Fumiyo.ikeda@imba.oeaw.ac.at

Running title: HOIP ubiquitination controls inflammation

Key words: Cell death/HOIP E3 ligase/linear ubiquitination/skin inflammation/TNF 


\begin{abstract}
HOIP, the catalytic component of the Linear Ubiquitin chain Assembly Complex (LUBAC), is a critical regulator of inflammation. However, how HOIP itself is regulated to control inflammatory responses is unclear. Here, we discover that site-specific ubiquitination of K784 within HOIP promotes Tumour Necrosis Factor (TNF)-induced inflammatory signalling by controlling TNF Receptor complex I (TNFR1) formation. A HOIP K784R mutant is catalytically active but shows reduced induction of an NF- $\mathrm{BB}$ reporter relative to wild type HOIP. HOIP K784 is evolutionarily conserved, equivalent to HOIP K778 in mice. We generated Hoip ${ }^{K 778 R / K 778 R}$ knockin mice, which show no overt developmental phenotypes; however, in response to TNF, Hoip ${ }^{K 778 R / K 778 R}$ mouse embryonic fibroblasts display suppressed NF- $\kappa B$ activation and increased sensitivity to apoptosis. On the other hand, HOIP K778R enhances the TNF-induced formation of TNFR complex II, and an interaction between TNFR complex II and LUBAC. Loss of the LUBAC component SHARPIN leads to embryonic lethality in Hoip ${ }^{K 778 R / K 778 R}$ mice, which is rescued by knockout of TNFR1. We propose that site-specific ubiquitination of HOIP regulates a LUBAC-dependent switch between survival and apoptosis in TNF-signalling.
\end{abstract}




\section{Introduction}

The Linear UBiquitin chain Assembly Complex (LUBAC) is a critical regulator of inflammation in humans and mice (Ikeda, 2015, Peltzer \& Walczak, 2019, Sasaki \& Iwai, 2015, Walczak, 2011). LUBAC influences the inflammatory response by regulating the tumour necrosis factor (TNF)signaling pathway. Upon TNF binding, the TNF receptor (TNFR) forms TNFR complex I (TNFR1), consisting of TNF Receptor type 1-Associated DEATH Domain (TRADD), Receptor-Interacting serine/threonine-Protein Kinase 1 (RIPK1), TNF Receptor-Associated Factor 2 (TRAF2), Cellular Inhibitor of Apoptosis Protein (cIAP) 1/2 and LUBAC. TNFR1 complex I promotes cell survival via

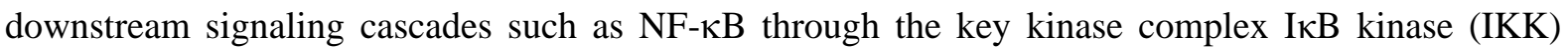
consisting of IKK1/2 and NF- $\mathrm{BB}$ Essential Modifier (NEMO). Post-translational modifications, including ubiquitination, regulate multiple events in this signaling cascade. Linear/Met1-, Lys11- and Lys63-ubiquitin linkage types regulate the recruitment of specific signaling complexes (Peltzer et al., 2016, Witt \& Vucic, 2017), whereas Lys48-linked ubiquitin chains trigger degradation by the ubiquitin-proteasome system. As part of TNFR complex I, LUBAC generates linear/Met1-ubiquitin chains on NEMO (Tokunaga et al, Haas et al 2009) and RIPK1 (Gerlach et al., 2011) to promote NF$\kappa \mathrm{B}$ signaling. NF- $\kappa \mathrm{B}$ activation leads to gene inductions of anti-apoptosis genes such as Cellular FLICE-like inhibitory Protein (cFLIP), thus known as anti-apoptosis pathway (Lamkanfi et al., 2007, Peltzer \& Walczak, 2019).

On the other hand, when NF- $\mathrm{BB}$ pathway is disturbed, TNF can promote apoptosis via formation of the TNFR complex II, which consists of RIPK1, TRADD, FAS-Associated Death Domain (FADD) and Caspase 8 (Justus \& Ting, 2015, Witt \& Vucic, 2017). TNFR complex II formation also appears to be regulated by LUBAC (Asaoka \& Ikeda, 2015, Peltzer \& Walczak, 2019, Sasaki \& Iwai, 2015), but the mechanisms are unclear.

LUBAC consists of the E3 ligase HOIP/RNF31, and two subunits HOIL-1L/RBCK1 and SHARPIN/SIPL1 (Gerlach et al., 2011, Ikeda et al., 2011, Rittinger \& Ikeda, 2017, Tokunaga et al., 2011). Genetic loss of HOIP or HOIL-1L triggers embryonic lethality in mice due to upregulation of apoptosis, uncovering their essential roles in mouse embryonic development and cell death regulation (Emmerich et al., 2013, Hrdinka \& Gyrd-Hansen, 2017, Peltzer et al., 2014) (Meier et al., 2015). In contrast, SHARPIN-deficient mice (Sharpin ${ }^{\text {cpdm/cpdm }}$ ) suffer from systemic inflammation accompanied with chronic proliferative dermatitis at the age of 6-8 weeks (Kumari et al., 2014, Seymour et al.,

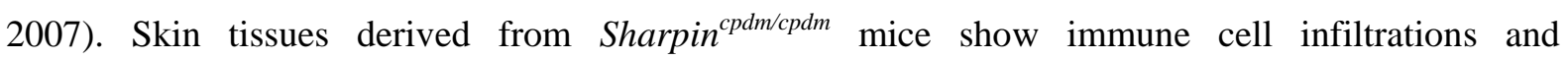
upregulation of keratinocyte apoptosis (Seymour et al., 2007). The phenotypes of these genetically modified mice are at least partially rescued by TNFR1 knockout, suggesting that LUBAC attenuates apoptosis downstream of the TNF signaling cascade (Kumari et al., 2014, Rickard et al., 2014). 
HOIL-1L and HOIP mutations are observed in patients with autoimmune diseases, implicating LUBAC in the regulation of immune responses in humans (Boisson et al., 2015, Boisson et al., 2012).

At the molecular level, HOIP is a RING-IBR-RING (RBR) type of E3 ligase that specifically generates linear/Met1-linked ubiquitin chains with SHARPIN and HOIL-1L. Linear ubiquitin chains are atypical chains linked via the C-terminal Gly of one ubiquitin moiety to the N-terminal Met1 of another ubiquitin moiety. The catalytic center of HOIP is in the second RING domain (Stieglitz et al., 2012), and the Linear Ub chain Determining Domain (LDD) domain provides its unique ability to generate linear ubiquitin chains (Smit et al., 2012). Thus far, HOIP is the only ligase known to generate linear ubiquitin chains (Dove \& Klevit, 2017, Kirisako et al., 2006).

In vitro, HOIP requires HOIL-1L or SHARPIN to generate linear ubiquitin chains (Gerlach et al., 2011, Ikeda et al., 2011, Kirisako et al., 2006, Tokunaga et al., 2011). However, the HOIP RBRLDD fragment is active in the absence of HOIL-1L and SHARPIN, suggesting a self-inhibitory mechanism (Smit \& Sixma, 2014, Walden \& Rittinger, 2018). LUBAC generates linear/Met1 ubiquitin chains at Lys on substrates, which depends on HOIL-1L (Smit et al., 2013). In cells, HOIP exists mostly in complex with SHARPIN or HOIL-1L (Kirisako et al., 2006, Tokunaga et al., 2011), thus, the LUBAC complex is expected to be active. Yet, the LUBAC-dependent downstream cascades are dependent on stimuli like TNF. The mechanisms that regulate LUBAC activity are unclear. In particular, it is not known how inflammatory stimuli modulate the interactions between LUBAC and its substrates.

Two deubiquitinases (DUBs), called "OTU DUB with LINear linkage specificity” (OTULIN) and CYLD, hydrolyze linear ubiquitin chains and regulate inflammatory signaling cascades. Both OTULIN and CYLD can form a complex with HOIP (Elliott et al., 2016, Elliott et al., 2014, Fiil et al., 2013, Hrdinka et al., 2016, Keusekotten et al., 2013, Kupka et al., 2016, Schaeffer et al., 2014, Takiuchi et al., 2014, Wagner et al., 2016). However, loss-of-function of OTULIN and CYLD in mice does not resulted in expected phenotypes compared with LUBAC-deficient mice (Damgaard et al., 2016, Reiley et al., 2006, Zhang et al., 2006); knockin mice expressing OTULIN C129A (a dominant negative mutant) are embryonic lethal with increased apoptosis signals, partially overlapping with mouse phenotype of HOIP and HOIL-1L knockout (Heger et al., 2018, Peltzer et al., 2018, Peltzer et al., 2014). Recently, it was shown that the OTULIN mutant Cys129Ala increases ubiquitination signal of all three LUBAC components (Heger et al., 2018). Hyper-ubiquitinated LUBAC in the OTULIN mutant Cys129Ala expressing cells is not recruited to TNFR complex I, leading to suppression of this branch of the TNF-induced signalling cascade (Heger et al., 2018).

These observations collectively suggest that LUBAC activity and linear ubiquitination of LUBAC components are tightly regulated. Yet, the posttranslational mechanisms controlling LUBAC and its inflammatory outcomes are poorly understood. 


\section{Results}

\section{Human HOIP is polyubiquitinated in cells}

To investigate how HOIP is regulated by ubiquitination, we transiently expressed Myc-HOIP in HEK293T cells. Linear ubiquitin chains were below the detection limit in HEK293T extracts (Fig S1A), which may reflect their deubiquitination. To stabilize linear ubiquitin chains, we co-expressed the catalytically inactive mutant of OTULIN C129A, which acts as a dominant negative (Heger et al., 2018). In addition, to enrich for proteins modified with linear ubiquitin chains, we performed a pulldown using a known enrichment matrix called GST-linear-TUBE, which consists of GST fused to three tandem repeats of the linear-ubiquitin binding domain UBAN immobilized on a glutathione sepharose resin (Fig 1A) (Asaoka et al., 2016). We detected modified HOIP in the pull-down by immunoblotting (Fig S1A, lane 8, and Fig 1B, lane 1) suggesting that HOIP is ubiquitinated at least partially by linear ubiquitin chains, as reported previously with Otulin ${ }^{\text {C129A/C129A }}$ knockin mouse embryonic fibroblasts (MEFs) (Heger et al., 2018).

To verify modification of HOIP, we used the Ubiquitin Chain Restriction (UbiCRest) method (Hospenthal et al., 2015), a DUB-based analysis (Fig 1A). The observed HOIP modification disappeared upon treatment with USP21, which hydrolyzes all linkage types of ubiquitin chains, verifying that the modification is ubiquitination (Fig 1B, lane 4). Treatment with either vOTU, which cleaves Lys-linked ubiquitin chains but not linear ubiquitin chains, or with OTULIN, which specifically cleaves linear ubiquitin chains, partially reduced the modification of HOIP (Fig 1B, lane 2 and 3). These data suggest that HOIP is polyubiquitinated with mixed linkage types of Lys and linear. OTULIN treatment diminished the levels of high-molecular weight HOIP, suggesting that linear ubiquitin chains are added on the Lys-linked ubiquitin chains.

Using mass spectrometry, we uncovered four ubiquitinated residues within human HOIP: lysine (K)454, K458, K735, K784 (Fig 1C-D, Fig S1B-D). K454 and K458 are not within any of the annotated HOIP domains and are not well-conserved (Fig 1D, Fig S1E). In contrast, K784 is within the "In Between Ring fingers" (IBR) domain, and K735 is located within the "Really Interesting New Gene" (RING1) domain (Fig 1D), and both residues are conserved in a wide range of species (Fig $1 \mathrm{E})$. 
To evaluate the functional role of these ubiquitination sites in HOIP, we generated HOIP K454R, K458R, K735R and K784R mutants. Given that LUBAC is a regulator of NF- $\mathrm{KB}$ signaling, we examined these HOIP mutants using standard NF- $\kappa \mathrm{B}$ reporter assays in which luciferase expression is under the control of NF-kB-response elements. Transfected cells expressed similar levels of wild type (WT) HOIP, the ubiquitination-site mutants (K454R, K458R, K735R, K784R), or a negative control (catalytically inactive mutant, C885A) (Fig 1F, S1F). As expected, we observed an increased luciferase signal in cells that co-express SHARPIN and HOIL-1L with HOIP WT, but not with HOIP C885A (Fig 1G). The luciferase signal was also significantly reduced in cells co-expressing HOIP K784R, whereas it was significantly increased, albeit mildly, in cells co-expressing HOIP K454R, K458R or K735R (Fig 1G). We observed similar results in assays without HOIL-1L or SHARPIN (Fig S1G and H).

We chose to pursue the HOIP K784 site, given that it is conserved and promotes NF- $\mathrm{KB}$ signaling. To investigate how linear ubiquitination at K784 affects LUBAC formation, we transiently co-expressed HOIP WT, HOIP C885A or HOIP K784R with HOIL-1L and SHARPIN in HEK293T cells, and analyzed interactions by co-immunoprecipitation. HOIP WT, HOIP K784R and HOIP C885A each interacted with HOIL-1L and SHARPIN (Fig 1F), suggesting that HOIP K784R supports LUBAC complex formation in cells. These data suggest that HOIP K784R reduces NF- $\kappa B$ reporter activity without compromising LUBAC complex formation.

\section{HOIP K784R generates unanchored linear ubiquitin chains and ubiquitinates NEMO}

According to crystal structure analysis, HOIP K784 is on the surface of an alpha helix in the IBR domain, not in contact with E2 ( $\mathrm{UbcH} 5$ ) or ubiquitin loaded on E2, and distant from the active site C885 (Lechtenberg et al., 2016). To determine how mutations in HOIP affect its activity, we purified recombinant HOIP proteins and performed in vitro ubiquitination assays. As expected, the HOIP C885A catalytic mutant did not generate unanchored linear ubiquitin chains nor did it ubiquitinate NEMO (Fig 2A, Fig S2A). Further, HOIP C885A was not polyubiquitinated (Fig 2A, Fig S2A), suggesting that HOIP is modified dependently on its own catalytic activity in vitro. Both HOIP WT and HOIP K784R generated unanchored linear ubiquitin chains and ubiquitinated the LUBAC substrate NEMO, when co-incubated with SHARPIN and HOIL-1L (Fig 2A). In the absence of SHARPIN, the ubiquitination signal was substantially reduced in reactions with HOIP K784R compared to HOIP WT (Fig S2A). These data suggest that the HOIP K784R mutant, in a complex with both HOIL-1L and SHARPIN, can ubiquitinate substrates in vitro, though with altered kinetics compared to HOIP WT. 
To test HOIP activity in cells, we transiently expressed HOIP WT, HOIP K784R or HOIP C885A with HOIL-1L and SHARPIN in HEK293T cells. Cells expressing HOIP WT and HOIP K784R displayed similar levels of linear ubiquitin chains and polyubiquitinated NEMO (Fig 2B), whereas cells expressing HOIP C885A lacked both ubiquitination events. These results collectively indicate that HOIP K784R, as a part of LUBAC, can ubiquitinate NEMO in vitro and in cells. The observations of HOIP ubiquitination dependent on its catalytic site C885 (Fig 2A and B) and HOIP ubiquitination by mixed linkage types of chains in cells (Fig 1B) suggest that HOIP ubiquitination is at least partially self-ubiquitination in cells.

\section{Hoip $^{\text {K778R/K778R }}$ mice do not have overt developmental defects}

Given that human HOIP K784R disrupted NF- $\mathrm{BB}$ signaling in the cellular reporter cell assay without substantially affecting HOIP catalytic activity or LUBAC formation in HEK293T cells, we investigated the endogenous function of HOIP K784 in vivo. We used CRISPR-Cas9 to generate homozygous knockin mice with a substitution at HOIP K778, the equivalent residue to K784 in mice $\left(\right.$ Hoip $^{K 778 R / K 778 R}$, Fig S3A and S3B). Hoip ${ }^{K 778 R / K 778 R}$ mice were born at the nearly expected ratio from crosses of Hoip $^{+/ K 778 R}$ mice and displayed no obvious developmental phenotypes (Fig 3A and B). These observations are in contrast to HOIP loss-of-function mice, which are embryonic lethal (Peltzer et al., 2014) (Emmerich et al., 2013) (Hrdinka \& Gyrd-Hansen, 2017).

\section{TNF-induced NF-KB activation is suppressed in Hoip $^{K 778 R / K 778 R}$ MEFs}

To analyze if HOIP K778 is involved in the regulation of TNF-dependent NF- $\kappa B$ signaling, we derived MEF lines from Hoip ${ }^{+/+}$and Hoip ${ }^{K 778 R / K 778 R}$ mice and stimulated them with TNF (Fig 3C and D, Fig S3C). We found that TNF-induced phosphorylation of I $\kappa \mathrm{B}-\alpha$ is prolonged and degradation of I $\kappa$ B- $\alpha$ was reduced in Hoip ${ }^{K 778 R / K 778 R}$ MEFs compared with Hoip ${ }^{+/+}$MEFs (Fig 3C). Furthermore, the

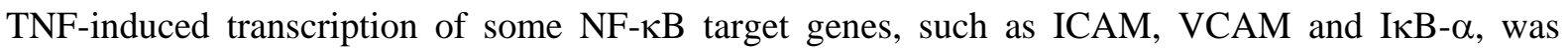
significantly reduced in Hoip ${ }^{K 778 R / K 778 R}$ MEFs compared to Hoip ${ }^{+/+}$MEFs (Fig 3D), whereas TNFinduced gene induction of A20 was unaffected (Fig S3C).

To elucidate the step of TNF-dependent signaling that is affected in Hoip ${ }^{K 778 R / K 778 R}$ MEFs, we examined the formation of TNFR complex I. Upon TNF-treatment, RIPK1, HOIP, SHARPIN, and NEMO co-immunoprecipitated with TNF in both Hoip $^{+/+}$and Hoip ${ }^{K 778 R / K 778 R}$ MEFs (Fig 3E), indicating recruitment to TNFR complex I. However, recruitment of RIPK1, HOIP and SHARPIN were mildly decreased in Hoip ${ }^{K 778 R / K 778 R}$ MEFs compared to WT MEFs (Fig 3E). 
Collectively, these data indicate that HOIP K778R significantly suppresses the TNF-induced NF- $\kappa \mathrm{B}$ signaling cascade in MEFs, coincident with slightly diminished formation of TNFR complex 1.

\section{Hoip $^{K 778 R / 778 K R}$ MEFs are sensitized to apoptosis}

LUBAC plays a role in the anti-apoptotic branch of the TNF pathway (Asaoka \& Ikeda, 2015, Sasaki \& Iwai, 2015, Walczak, 2011). Therefore, we assessed the ability of Hoip ${ }^{K 778 R / K 778 R}$ MEFs to resist TNF-dependent cell death. To this end, we examined TNF-mediated induction of the active form of Caspase 3 (cleaved-Caspase 3), which is a so-called apoptosis executioner caspase, and cleavage of its substrate, PARP (Fig 3F). We also treated cells with cycloheximide (CHX), an inhibitor of translation which sensitizes cells to TNF-induced apoptosis (Kumari et al., 2014, Rahighi et al., 2009). Compared to Hoip $^{+/+}$MEFs, Hoip ${ }^{K 778 R / K 778 R}$ MEFs displayed elevated levels of both cleaved-Caspase 3 and cleaved PARP after treatment with TNF and CHX (Fig 3F).

We also measured the activity of an apoptosis initiator caspase, Caspase 8, using luminescent assays in $\mathrm{Hoip}^{+/+}$and Hoip ${ }^{\text {K778R/K778R }}$ primary MEFs. We observed significantly higher levels of Caspase 8 activity in Hoip ${ }^{K 778 R / K 778 R}$ MEFs than in $\mathrm{Hoip}^{+/+}$MEFs after treatment with TNF and CHX (Fig 3G). Similar responses were observed in MEFs treated with a different cell death ligand, Fasligand (FasL) (Fig S3D). As expected, treatment with the pan-caspase inhibitor z-VAD eliminated Caspase 8 activity (Fig 3G, Fig S3D).

TNF- and FasL-induced apoptosis pathways are mediated through the TNFR complex II and the death-inducing signaling complex (DISC), respectively. These signaling pathways have overlapping components including FADD and Caspase 8. Thus, we hypothesized that HOIP K784 ubiquitination regulates those cell death-inducing complexes. To address this point, we examined TNFR complex II formation in Hoip ${ }^{+/+}$and Hoip ${ }^{K 778 R / K 778 R}$ MEFs. We treated MEFs with TNF, CHX and $\mathrm{z}-\mathrm{VAD}$ and immunoprecipitated the TNFR complex II component FADD. We observed an enhanced complex formation between FADD and RIPK1, HOIP and SHARPIN in Hoip ${ }^{\text {K778R/K778R }}$ MEFs compared to $\mathrm{Hoip}^{+/+}$MEFs. Thus, formation of the TNFR complex II in response to TNF and CHX is elevated in Hoip ${ }^{K 778 R / K 778 R}$ MEFs compared to Hoip ${ }^{+/+}$MEFs.

\section{Hoip $^{\text {K778R/K778R }}$; Sharpin ${ }^{c p d m / c p d m}$ mice display TNFR1-dependent embryonic lethality}

Given that Hoip ${ }^{K 778 R / K 778 R}$ MEFs are sensitized to TNF-induced apoptosis, and that the LUBAC component SHARPIN plays a role in the same apoptosis pathway (Ikeda et al., 2011), we investigated a potential cooperation between HOIP and SHARPIN in vivo. To this end, we attempted to generate 
Hoip ${ }^{K 778 R / K 778 R}$ mice in the Sharpin ${ }^{\text {cpdm/cpdm }}$ background, which do not express functional SHARPIN protein. We did not observe any Hoip ${ }^{K 778 R / K 778 R}$;Sharpin ${ }^{\text {cpdm/cpdm }}$ newborn mice from a cross of Hoip $^{+/ K 778 R}$;Sharpin ${ }^{+/ c p d m}$ mice (Fig 4A), suggesting embryonic lethality. To examine the embryonic development of Hoip $^{K 778 R / K 778 R}$;Sharpin ${ }^{\text {cpdm/cpdm }}$ mice, we crossed Hoip ${ }^{K 778 R / K 778 R}$; Sharpin $^{+/ c p d m}$ mice and analyzed embryos at E12.5 and E13.5 (Fig 4B and C, Fig S4A). We observed embryos of all genotypes at both these stages (Fig 4B). However, Hoip ${ }^{K 778 R / K 778 R}$; Sharpin ${ }^{\text {cpdm/cpdm }}$ embryos were found to be unhealthy with grossly evident regions of hemorrhage, suggesting the possibility of lethality at, or immediately subsequent to, these stages (Fig S4A, Fig 4C).

Sharpin ${ }^{\text {cpdm/cpdm }}$ mice display a systemic inflammatory phenotype that requires TNFR1 (Kumari et al., 2014, Rickard et al., 2014). To elucidate if the embryonic lethality of Hoip $^{K 778 R / K 778 R} ;$ Sharpin ${ }^{\text {cpdm/cpdm }}$ mice also depends on TNFR1, we tested whether it is rescued by TNFR1 knockout. Strikingly, the embryonic lethality is rescued in Hoip $^{K 778 R / K 778 R} ;$ Sharpin $^{\text {cpdm/cpdm }} ;$ Tnfr $1^{-/}$mice (Fig 4D), and skin inflammation was nearly absent until at least 8 weeks after birth (Fig 4E). Furthermore, qualitative reduction of inflammation in tissues such as the lung and liver was also observed in 8-week old Hoip $^{K 778 R / K 778 R}$;Sharpin ${ }^{\text {cpdm/cpdm }}$; Tnfrl ${ }^{-/-}$mice (Fig S4B).

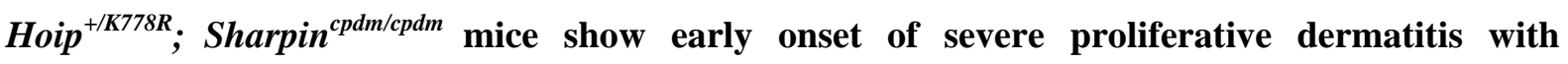 keratinocyte apoptosis}

Remarkably, heterozygosity of $\mathrm{Hoip}^{+/ K 778 R}$ was sufficient to bring about an early onset of dermatitis in Sharpin ${ }^{\text {cpdm/cpdm }}$ mice (Fig 4D and E, Fig 5A and B). At 4 weeks of age, these mice developed chronic proliferative dermatitis characterized by acanthosis, hyperkeratosis, dermal inflammatory cell infiltrates and keratinocyte apoptosis (detected by cleaved Caspase 3). The acanthosis was further confirmed by the thickened Keratin 14 (KRT14) positive zone in the epidermis (Fig 4E). In contrast, Hoip $^{+/+}$;Sharpin ${ }^{\text {cpdm/cpdm }}$ mice showed no clear sign of skin lesions at this age (Fig 5A and B). The extent of the chronic proliferative dermatitis in $\mathrm{Hoip}^{+/ K 778 R}$; Sharpin $^{\text {cpdm/cpdm }}$ mice was further quantified by measurements of total epidermal thickness, keratin layer thickness and squamous epithelial layer thickness (Fig5 C-E). Increased dermal inflammatory cell infiltration in Hoip $^{+/ K 778 R}$;Sharpin ${ }^{\text {cpdm/cpdm }}$ mice was further confirmed by the macrophage marker, F4/80, and the monocyte/granulocyte/neutrophil maker Ly6G (Fig 5B). Importantly, apoptotic epidermal keratinocytes with activated Caspase 3 positivity were also prominent in these skin sections (Fig 5B, Cleaved Caspase 3 panels). These features resemble those of Sharpin ${ }^{\text {cpdm/cpdm }}$ mice at an older age (8week old). In addition to the skin, Hoip ${ }^{+/ K 778 R} ;$ Sharpin $^{\text {cpdm/cpdm }}$ mice showed a multi-systemic inflammatory phenotype with immune cell infiltrates in visceral organs such as the lung and liver (Fig

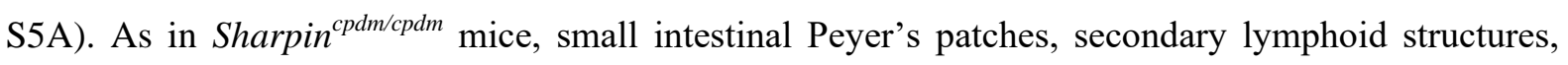


were notably absent in Hoip $^{+/ K 778 R} ;$ Sharpin ${ }^{\text {cpdm/cpdm }}$ mice (Fig S5A). In contrast to the enlarged spleens in Sharpin ${ }^{\text {cpdm/cpdm }}$ mice, spleens were smaller in Hoip $^{+/ K 778 R}$;Sharpin ${ }^{\text {cpdm/cpdm }}$ (Fig S5B). In the spleens

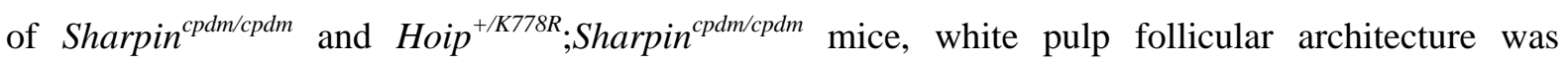
obscured in concert with enhanced myeloid hyperplasia in the red pulp (Fig S5A, S5B). The skin inflammatory phenotype of Hoip $^{+/ K 778 R}$;Sharpin ${ }^{\text {cpdm/cpdm }}$ mice was mitigated by TNFR1 knockout (Fig 4D and E). These results collectively suggest that ubiquitination of HOIP at K778 in mice collaborates with SHARPIN to regulate TNF-induced inflammation and cell death.

To test whether the TNFR1-dependent inflammation and apoptosis phenotypes in Hoip $^{+/ K 778 R}$;Sharpin ${ }^{\text {cpdm/cpdm }}$ mice are cell autonomous, we established immortalized MEFs and examined TNF-induced signaling cascades, including NF- $\mathrm{KB}$ activation and apoptosis (Fig 5F-H). TNF-induced degradation of IאB- $\alpha$ was further delayed in Hoip $^{+/ K 778 R} ;$ Sharpin $^{\text {cpdm/cpdm }}$ MEFs, similar to Hoip ${ }^{K 778 R / K 778 R}$ MEFs and Sharpin ${ }^{\text {cpdm/cpdm }}$ MEFs (Fig 5F). Cleaved PARP, cleaved Caspase 3 and activated Caspase 8 were elevated in $\mathrm{Hoip}^{+/ K 778 R}$;Sharpin ${ }^{\text {cpdm/cpdm }}$ MEFs compared to Hoip ${ }^{+/+}$MEFs, Hoip ${ }^{K 778 R / K 778 R}$ MEFs and Sharpin ${ }^{\text {cpdm/cpdm }}$ MEFs treated with TNF, particularly without CHX (Fig $5 \mathrm{G}$ and $\mathrm{H}$ ). We observed similar results with primary ear-derived fibroblasts (Fig S5C). These results indicate that HOIP ubiquitination at K778 cooperates with SHARPIN to promote TNF-induced cell survival in a cell autonomous manner.

\section{Discussion}

Our findings demonstrate that a site-specific ubiquitin modification of HOIP (K784 in human, K778 in mouse) cooperates with SHARPIN to impact TNF-dependent signaling cascades and immune responses in mice (Fig 6). Importantly, HOIP K784R is still ubiquitinated at other sites, both in cells and in vitro, emphasizing a specific requirement for ubiquitination at K784. TNFR1 knockout rescues the mouse phenotypes arising from HOIP K778R and SHARPIN-deficiency, indicating the dependency on TNFR1 signalling. The K-to-R substitution in HOIP (K784R in human or K778R in mouse) did not alter HOIP levels, indicating that ubiquitination at this site does not regulate proteasomal degradation.

Hoip ${ }^{K 778 R / K 778 R}$ knockin mice, generated in this study, manifest no overt phenotype for at least 96 weeks after birth. Consistent with our NF- $\mathrm{BB}$ gene reporter assays using HOIP K784R, we found that TNF-induced NF- $\kappa \mathrm{B}$ activation was suppressed in Hoip ${ }^{K 778 R / K 778 R}$ cells compared to Hoip ${ }^{+/+}$cells. Since the recruitments of HOIP, SHARPIN and modified and unmodified-RIPK1 to TNFR complex I were mildly reduced, we speculate that this site-specific ubiquitination of HOIP might regulate TNFR complex I formation in cells. Apoptosis induced by TNF and CHX was clearly enhanced in Hoip ${ }^{K 778 R / K 778 R}$ cells. FADD showed enhanced interactions with RIPK1, HOIP and SHARPIN in the 
TNFR complex II in Hoip ${ }^{K 778 R / K 778 R}$ cells relative to wild type cells, after treatment with TNF and CHX. These data suggest that ubiquitination of HOIP at K778 (in mice) plays a critical role in the apoptosis pathway by regulating the formation of downstream signalling complexes.

Embryonic lethality was observed in Hoip ${ }^{K 778 R / K 778 R}$ knockin mice with concurrent loss of SHARPIN. Additionally, regions of hemorrhage were grossly evident in Hoip $^{\text {K778R/K778R }}$;Sharpin ${ }^{\text {cpdm/cpdm }}$ embryos at the E12.5-E13.5 stages. HOIP and HOIL-1L are critical for embryonic development in mice, and mouse knockouts of these LUBAC components result in hyperinduction of apoptosis in embryos (Peltzer et al., 2018, Peltzer et al., 2014). Strikingly, a heterozygous allele of $\mathrm{Hoip}^{+/ K 778 R}$ is sufficient to accelerate skin inflammation and apoptosis in SHARPIN-deficient mice. These data indicate collaborative roles of SHARPIN and HOIP site-specific ubiquitination at K784.

Based on the known co-crystal structure of the HOIP-C-terminal fragment with ubiquitinloaded E2 (UbcH5), HOIP K784 within the IBR domain does not directly contact the ubiquitin or E2 (Lechtenberg et al., 2016). Furthermore, our in vitro ubiquitination assays using recombinant LUBAC components suggest that the suppressed activity of the NF- $\mathrm{BB}$ gene reporter is not due to substantial loss of LUBAC activity. However, in vitro reactions lacking SHARPIN show that linear ubiquitination is reduced with HOIP K784R relative to HOIP WT, which could in part explain why HOIP K784R knockin mice with no apparent phenotype become embryonic lethal with SHARPINdeficiency. We observed complete loss of ubiquitination of HOIP C885A relative to HOIP WT, indicating that HOIP ubiquitination relies on its catalytic activity. However, the E3 ligases that directly ubiquitinate HOIP in the TNF signalling cascade in cells is not known. HOIP is modified by mixed-linkage types of linear and Lys-linked ubiquitin chains in cells, suggesting that additional E3 ligases are involved.

A method to generate a ubiquitination mimic of the substrate to directly address the impact of site-specific ubiquitination, especially by 'poly'ubiquitination is not yet established. Thus, we mutated HOIP K784 to abolish ubiquitination at this site. Although any mutation can yield non-specific negative effects, HOIP K784R retained catalytic activity but altered the TNF-induced inflammatory by diminishing TNFR complex I but enhancing TNFR complex II formation and function. Thus, the effects we observed with HOIP K784R mutant in cell signalling are not due to non-specifics on protein folding.

Deubiquitinases are known to regulate HOIP-ubiquitination. In a previous study, expression of inactive OTULIN C129A mutant in cells leads to hyper-ubiquitination of LUBAC components, including HOIP, and prevents proper activation of TNF-induced signalling (Heger et al., 2018). We now show that site-specific ubiquitination of HOIP influenced TNFR complex formation. As a next 
step, it would be important to understand how the balance of OTULIN and LUBAC is controlled in different cell types to regulate immune responses.

In conclusion, our study has uncovered a new type of regulation of the ubiquitin ligase HOIP by site-specific ubiquitination, which is balances inflammatory responses by promoting the formation of TNFR complex I and inhibiting the formation of TNFR complex II. Similar to the regulation of kinases by phosphorylation, site-specific ubiquitin modification of ubiquitin ligases might regulate their activity and function in biology.

\section{Materials and methods}

\section{Plasmids}

pBABE-puro-Flag-human SHARPIN, pEGFP-C1-human SHARPIN, pGEX-6P-1-human HOIP, pGEX-4T-1-Linear TUBE, pGEX-6P-1-human OTULIN (WT and C129A), and pcDNA3-humanUbiquitin were previously described (Asaoka et al., 2016, Ikeda et al., 2011). pGEX-6P-1-human NEMO, pGEX-6P-1-human HOIL-1L, pGEX-6P-1-human SHARPIN and pRK5-Myc-human OTULIN (WT and C129A) were cloned using a standard subcloning method. All the point mutants in pcDNA3-Myc-human HOIP (K454R, K458R, K735R, K784R and C885A) and pGEX-6P-1-human HOIP (K784R and C885A) were generated by site directed mutagenesis. Sequences of all the plasmids generated for this study were confirmed by Sanger sequencing. pcDNA3-Myc-human HOIP and pcDNA3-human-HOIL-1L-HA were from Kazuhiro Iwai (Tokunaga et al., 2009), pGex6P-1human UbcH7, pET49b-human HOIP UBA-RBR-C (aa 476-1072) and pET49b-human HOIL-1L (C460A) were from Katrin Rittinger (Stieglitz et al., 2012). pOPINK-vOTU (CCHFV OTU, aa1-183) (Addgene plasmid \#61589) (Akutsu et al., 2011) and pOPINS-USP21 (USP, aa 196-565) (Addgene plasmid \#61585)(Ye et al., 2011) were gifts from David Komander.

Primer sequences used for the site-directed mutagenesis were the following.

HOIP K454R: forward primer 5'-GCCAGCTCTTTGGAAAGGGGACCCCCCAAG-3', reverse primer 5'-CTTGGGGGGTCCCCTTTCCAAAGAGCTGGC-3', HOIP K458R: forward primer 5'GAAAAGGGACCCCCCAGGCCTGGGCCCCCA-3', reverse primer 5'TGGGGGCCCAGGCCTGGGGGGTCCCTTTTC-3', HOIP K735R: forward primer: CACTTCACCATCGCCTTGAGGGAGAAGCACATC-3', reverse primer 5'GATGTGCTTCTCCCTCAAGGCGATGGTGAAGTG-3', HOIP K784R forward primer 5'GCGTTGTTCCATAAGAGGCTGACCGAGGG-3', CCCTCGGTCAGCCTCTTATGGAACAACGC-3', HOIP C885A: forward Primer 5'GCCCGAGGAGGCGCCATGCACTTTCACTGTACC-3', GGTACAGTGAAAGTGCATGGCGCCTCCTCGGG-3’ 


\section{Antibodies and reagents}

The following antibodies were purchased and used according to the manufacturer's instructions: antiMyc (9E10) antibody (Covance, MMS-150P), anti-HA (HA.11 clone 16B12) antibody (Covance, MMS-101P), anti-Flag (M2) antibody (Sigma, F3165), anti-vinculin antibody (Sigma-Aldrich, V9131), anti-alpha-tubulin antibody (Abcam, ab15246), anti-ubiquitin (P4D1) antibody (Santa Cruz Biotechnology, sc-8017), anti-linear ubiquitin (LUB9) antibody (Life Sensors, \#AB130), and antilinear ubiquitin (LUB4) antibody (a kind gift from Japan Tobacco Inc. Pharmaceutical Frontier laboratories), anti-HOIP antibodies used for the detection of human HOIP (Aviva systems biology, ARP43241_P050, and Sigma, SAB2102031), anti-HOIL-1L antibody (Merck Millipore, MABC576), anti-SHARPIN antibody (Novus, NBP2-04116), anti-Fam105b/OTULIN antibody (Abcam, ab151117), anti-NEMO/IKK $\gamma$ antibody (FL-419) (Santa Cruz, sc-8330), anti-IkB- $\alpha$ antibody (Cell Signaling, \#4812), anti-pIкB- $\alpha$ antibody (Cell Signaling, \#9246), anti-PARP antibody (Cell Signaling, \#9542), anti-cleaved Caspase 3 antibody (Cell Signaling, \#9664), anti-FADD antibody used for immunoprecipitation (Santa Cruz, sc-271748), anti-FADD antibody used for detection of FADD by immunoblotting (Abcam, ab124812), and anti-RIPK1 antibody (Cell signaling, \#3493), and antiphospho-RIPK1 antibody (Cell Signaling, \#31122). A polyclonal antibody against mouse HOIP was raised against a recombinant protein containing a mouse HOIP fragment (aa 475-625) by immunizing rabbit (immunoGlobe, Germany). Secondary antibodies used for the immunoblotting are Goat antiMouse IgG-HRP (Bio-Rad, 170-6516) and goat anti-Rabbit IgG-HRP (Dako, P0448). Secondary antibodies used for immunoprecipitation were Protein G Agarose beads (Roche, 1124323301) and anti-FLAG (M2) beads (Sigma Aldrich, A2220)

Recombinant human Flag-TNF (Enzo, ALX-522-008-C050), recombinant human TNF (Peprotech, 300-01A), recombinant human TRAIL (Peprotech, 310-04), Lipopolysaccharide (LPS) (Sigma Aldrich, L4391), Cycloheximide (CHX) (Sigma Aldrich, C4859) and Z-Val-Ala-DL-Asp(Ome)fluoromethylketone (z-VAD-fmk) (Bachem, N-1560) were also used. Recombinant Fc-Fas ligand was a kind gift from Pascal Schneider (Schneider et al., 1997).

\section{Tissue culture and transfection}

Human embryonic kidney 293T (HEK293T) (ATCC) and immortalized MEFs were maintained at $37^{\circ} \mathrm{C}$ in $5 \% \mathrm{CO}_{2}$ in Dulbecco's modified Eagle's medium (DMEM) (Sigma, D5648) supplemented with $10 \%$ fetal calf serum (ThermoFisher Scientific, 10270106), 1\% L-glutamine (ThermoFisher Scientific, 25030-024), and 1\% penicillin-streptomycin (Sigma, P0781). PCR-based mycoplasma tests confirmed all cells to be negative for mycoplasma contamination. Transfections in HEK293T or MEFs were performed using GeneJuice (Merck Millipore, 70967) according to the manufacturer's protocol.

\section{Isolation and immortalization of mouse embryonic fibroblasts (MEFs)}


Primary MEFs were isolated from E13.5 embryos (C57BL/6J Hoip ${ }^{+/+}$and Hoip ${ }^{\text {K778R/K778R }}$, C57BL/6J/KaLawRij Hoip ${ }^{+/+}$; Sharpin ${ }^{+/+}$, Hoip ${ }^{\text {K778R/K778R }}$; Sharpin $^{+/+}$, Hoip $^{+/+}$; Sharpin ${ }^{\text {cpdm/cpdm }}$, and Hoip ${ }^{K 778 R /+}$; Sharpin ${ }^{\text {cpdm/cpdm }}$ ) according to a standard protocol (Ikeda et al., 2011).

\section{Isolation of primary mouse dermal adult fibroblasts (MDFs)}

Primary mouse dermal adult fibroblasts (MDFs) were isolated from ear tissue derived from mice at four weeks of age. Ear tissue was washed in $70 \%$ ethanol, air dried and minced into small pieces using a scalpel. Tissue pieces were collected in Dulbecco's modified Eagle's medium (DMEM) (Sigma, D5648) supplemented with 10\% fetal calf serum (ThermoFisher Scientific, 10270106,) 1\%

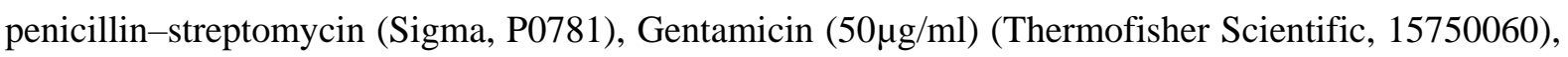
and 1\% MEM non-essential amino acid solution (Thermofisher Scientific, 11140050) and centrifuged at 1,500 rpm for 5 minutes. Trypsin (Thermofisher scientific, 25300054) treated tissue pieces were incubated for 1 hour at $37^{\circ} \mathrm{C}$, with a vortex step performed every 15 minutes. Fresh media was added and the tissue pieces were centrifuged, resuspended in fresh media and plated in a tissue culture dish. MDFs were seeded for cellular assays upon reaching confluency.

\section{Cell lysis}

A method is described elsewhere (Ikeda et al., 2011). Briefly, cells were lysed in chilled lysis buffer (50mM HEPES (pH7.4) (Sigma Aldrich, H4034), 150mM NaCl, 1mM EDTA, 1mM EGTA, 1\% Triton X-100, 10\% Glycerol, 25mM NAF and $10 \mu \mathrm{M} \mathrm{ZnCl2,} 1$ x cOmplete protease inhibitor cocktail (Roche, 11836170001), 1mM PMSF (Roche, 10837091001) and 10mM NEM (Sigma-Aldrich, E3876) on ice. Lysates were cleared by centrifugation at 15,000 rpm for 15 minutes. For denaturing conditions, cells were lysed in $1 \%$ SDS-PBS and boiled at $96^{\circ} \mathrm{C}$ for 10 minutes as described before (Sasaki et al., 2015). Subsequently, lysates were sheared through a 27 3/4G needle (Becton Dickinson, BD 302200) several times, centrifuged at 15,000 rpm for 5 minutes (at room temperature) and the supernatant was subjected for further analysis.

\section{Immunoprecipitation}

For immunoprecipitation of Myc-HOIP, anti-Myc antibody $(1 \mu \mathrm{g})$ was incubated for 2 hours at $4{ }^{\circ} \mathrm{C}$, followed by incubation with Protein G Agarose beads (Roche, 1124323301) $(15 \mu \mathrm{l})$ for 2 hours at $4^{\circ} \mathrm{C}$. Beads were washed four times in lysis buffer. Proteins were eluted from beads using 30 $\mu 1$ of $2 \mathrm{X}$ SDS sample buffer and heated at $96^{\circ} \mathrm{C}$ for 5 minutes.

A method for immunoprecipitation of the TNFR complex I is described in previous studies (Draber et al., 2015, Haas et al., 2009). Briefly, after serum starvation in 0.2\% FCS-DMEM for 15 hours, MEFs $\left(5-20 \times 10^{6}\right.$ cells) were treated with $1 \mu \mathrm{g} / \mathrm{ml}$ of Flag-human TNF, washed by PBS twice, and lysed in $1 \mathrm{ml}$ of chilled IP-Lysis buffer (30mM Tris-HCI (pH7.4), 120mM NaCl, 2mM EDTA, 2mM KCI, $10 \%$ glycerol, $1 \%$ Trition X-100, 50mM NaF, 1 x cOmplete protease inhibitor cocktail (Roche, 
11836170001), 1mM PMSF (Roche, 10837091001), 10mM NEM (Sigma-Aldrich, E3876), and 5mM $\mathrm{NAVO}_{4}$ (Sigma-Aldrich, S6508)) for 30 mins on ice. Lysates were centrifuged at 15,000 rpm for 30 minutes at $4^{\circ} \mathrm{C}$. Flag-human TNF $(1 \mu \mathrm{g})$ was added to the $0 \mathrm{hr}$ control samples. After preclearing with Protein G Agarose beads for 1 hour at $4^{\circ} \mathrm{C}$, anti-FLAG (M2) beads (Sigma Aldrich, A2220) (10 $\mu$ l of beads slurry) were incubated for 16 hours at $4^{\circ} \mathrm{C}$, washed five times with the IP-Lysis Buffer and denatured for five minutes at $96^{\circ} \mathrm{C}$ in $2 \mathrm{X}$ SDS sample buffer.

A method for immunoprecipitation of TNFR complex/complex II is described elsewhere (Ang \& Ting, 2018). Briefly, MEFs $\left(5-20 \times 10^{6}\right)$ were treated with human TNF (100ng/ml), z-VAD-fmk $(25 \mu \mathrm{M})$ and cycloheximide $(1 \mu \mathrm{g} / \mathrm{ml})$ for the indicated times and lysed in chilled DISC-IP buffer (150mM NaCl, 20mM Tris-HCL pH 7.5, 1mM EDTA, 0.2\% NP40, 10\% glycerol supplemented with cOmplete protease inhibitor cocktail (Roche, 11836170001), 0.1mM Na $3 \mathrm{VO}_{4}$ (Sigma-Aldrich, S6508), 100mM NEM (Sigma-Aldrich, E3876), 1mg/ml of BSA (VWR International, 422351S) for 10 minutes on ice. Lysates were centrifuged at $15,000 \mathrm{rpm}$ for 15 mins and supernatant was precleared with Protein $\mathrm{G}$ Agarose beads $(25 \mu \mathrm{l})$ for 1.5 hours at $4^{\circ} \mathrm{C}$, followed by immunoprecipitation with $\alpha$-FADD antibody $(2 \mu \mathrm{g})$ (Santa Cruz; sc-271748) incubation for 16 hours at $4^{\circ} \mathrm{C}$. Subsequently, Protein $\mathrm{G}$ Agarose beads $(25 \mu \mathrm{l})$ incubation for 1.5 hours at $4^{\circ} \mathrm{C}$. Immunoprecipitated samples were washed four times with DISC-IP buffer. Samples were heated at $70^{\circ} \mathrm{C}$ for 20 minutes in $2 \mathrm{X}$ SDS sample buffer.

\section{GST-Linear TUBE pulldown}

GST-Linear TUBE pulldown was performed as previously described (Asaoka et al., 2016). Briefly, cells were lysed in mammalian lysis buffer on ice and cleared by centrifugation. GST-empty and GST-Linear TUBE immobilized on glutathione Sepharose 4B beads were incubated with supernatants for 12 hours at $4{ }^{\circ} \mathrm{C}$. Pulldown samples were washed five times in lysis buffer, and heated at $96^{\circ} \mathrm{C}$ for 5 minutes in $2 X$ SDS sample buffer.

\section{Immunoblotting}

The protocol used for immunoblotting was described previously (Ikeda et al., 2011) (Kumari et al., 2014). Briefly, samples were resolved by SDS-PAGE, and transferred to a nitrocellulose membrane (GE Healthcare, 10600019 or 10600001). The membrane was proceeded with Ponceau S (Roth, 5938.1) staining to monitor the transferred proteins. Membranes were washed, blocked with 5\% BSATBS, and blotted with the indicated primary antibodies diluted in 5\% BSA-TBS at $4^{\circ} \mathrm{C}$ overnight. Subsequently, membranes were incubated with a secondary antibody according to the manufacturer's instructions, and signal was detected with Western Blotting Luminol Reagent (Santa Cruz; sc-2048) on high-performance chemiluminescence films (GE Healthcare, Amersham Hyperfilm ECL, 28906837). 


\section{Luciferase-based NF-kB gene reporter assay}

HEK293T cells were seeded in 96-well plates $\left(1 \times 10^{4}\right.$ cells/well) (Thermoscientific, 136101) and transfected with pNF-kB-Luc (Stratagene) and phRK-TK (Renilla) (Promega) using GeneJuice (Merck Millipore, 70967). After 48 hours, samples were subjected to a luciferase assay using the Dual-Glo Luciferase Assay System (Promega; E2940) according to the manufacture's protocol. Luciferase and Renilla signal were measured by the Synergy H1 hybrid multimode microplate reader (BioTek) and monitored by Gen5 software. Each experimental sample was carried out in quadruplicate and normalized to the Renilla signal.

\section{Protein Purification}

A method is described elsewhere (Asaoka et al, 2016; Ikeda et al, 2011). Briefly, plasmids were transformed into BL21 (DE3) E.coli. Bacterial cells were grown in the LB media at $37^{\circ} \mathrm{C}$. Expression of GST tagged fusion proteins were induced using $100 \mu \mathrm{M}$ IPTG (Thermoscientific, R0392) at $\mathrm{OD}_{600}=$ 0.8 in 4-6 litres of culture. $100 \mu \mathrm{M} \mathrm{ZnCl}_{2}$ (Sigma-Aldrich, 229997) was added during induction of HOIP, HOIL-1L and SHARPIN expression only. Cultures were grown overnight at $18^{\circ} \mathrm{C}$. Cells were centrifuged and resuspended in the suspension buffer (100mM HEPES (Sigma Aldrich, H4034), $500 \mathrm{mM} \mathrm{NaCl}, 1 \mathrm{mM}$ TCEP-HCl (ThermoScientific, 20491) pH 7.4 which was supplemented with recombinant DNase I (1000U) (Roche,04536282001), cOmplete protease EDTA-free inhibitor cocktail (Roche, Roche, 11836170001) and 1mM PMSF (100mM in isopropanol, Roche, 10837091001). Cells were sonicated and 0.5\% Triton X-100 was added to the lysate. The lysate was cleared by centrifugation and applied to a $5 \mathrm{ml}$ GSTrap FF column (GE Healthcare, 17513101) to initially purify GST-proteins. The GST-tag was removed by overnight oncolumn cleavage with the PreScission Protease (homemade). Protein eluates were further resolved using size exclusion chromatography on gel filtration columns using the Superdex 200 (16/600) (GE Healthcare,GE28-9893-35) or Superdex 75 (16/600) (GE Healthcare, GE28-9893-33) in a buffer containing 50mM HEPES (Sigma Aldrich, H4034), 150mM NaCl, 1mM TCEP-HCl (ThermoScientific, 20491), pH 7.4. Eluted fractions were analysed in SDS-PAGE stained with InstantBlue ${ }^{\mathrm{TM}}$ Protein Stain (Expedeon, 1SB1L) and the fractions containing the desired protein were pooled together. Proteins were concentrated using a Vivaspin concentrator (Sartorius) with a half lower MWCO than the size of the protein being purified. Protein concentrations were determined by UV absorption at $280 \mathrm{~nm}$ using calculated extinction coefficients or compared to known BSA standards visualized by SDS-PAGE and stained with Instant Blue. A baculovirus for insect expression of His $_{6}$ - mouse Ube1 in Hi5 cells was a kind gift from Kazuhiro Iwai and was expressed and purified as previously described (Iwai, Yamanaka et al., 1999).

\section{NanoLC-MS Analysis}


Samples containing HOIP were separated using SDS-PAGE using 4-15\% Mini-PROTEAN TGX gels (Bio-Rad; \#4561083). Gels were silver stained according to Blum's protocol (Helmut et al., 1987). Gel fragments containing the HOIP band and above were extracted from the gel. Following this, the gel bands were reduced, alkylated and digested with Trypsin.

The nano HPLC system used was an UltiMate 3000 RSLC nano system (Thermo Fisher Scientific, Amsterdam, Netherlands) coupled to a Q Exactive Plus mass spectrometer (Thermo Fisher Scientific, Bremen, Germany), equipped with a Proxeon nanospray source (Thermo Fisher Scientific, Odense, Denmark). Peptides were loaded onto a trap column (Thermo Fisher Scientific, Amsterdam, Netherlands, PepMap C18, $5 \mathrm{~mm} \times 300 \mu \mathrm{m}$ ID, $5 \mu \mathrm{m}$ particles, $100 \AA$ pore size) at a flow rate of 25 $\mu \mathrm{L}$ min-1 using $0.1 \%$ TFA as mobile phase. After $10 \mathrm{~min}$, the trap column was switched in line with the analytical column (Thermo Fisher Scientific, Amsterdam, Netherlands, PepMap C18, $500 \mathrm{~mm} \times$ $75 \mu \mathrm{m}$ ID, $3 \mu \mathrm{m}, 100 \AA$ ). Peptides were eluted using a flow rate of $230 \mathrm{nl} \mathrm{min-1}$ and a binary $1 \mathrm{~h}$ gradient, respectively $105 \mathrm{~min}$.

The gradient starts with the mobile phases: 98\% A (water/formic acid, 99.9/0.1, v/v) and 2\% B (water/acetonitrile/formic acid, 19.92/80/0.08, v/v/v), increases to $35 \% \mathrm{~B}$ over the next $60 \mathrm{~min}$, followed by a gradient in $5 \mathrm{~min}$ to $90 \% \mathrm{~B}$, stays there for $5 \mathrm{~min}$ and decreases in $5 \mathrm{~min}$ back to the gradient $98 \% \mathrm{~A}$ and $2 \% \mathrm{~B}$ for equilibration at $30^{\circ} \mathrm{C}$.

The Q Exactive Plus mass spectrometer was operated in data-dependent mode, using a full $\mathrm{scan}(\mathrm{m} / \mathrm{z}$ range 380-1650, nominal resolution of 70,000, target value 3E6) followed by MS/MS scans of the 12 most abundant ions. MS/MS spectra were acquired using normalized collision energy of $27 \%$, isolation width of $2.0 \mathrm{~m} / \mathrm{z}$, resolution of 17.500 and the target value was set to $1 \mathrm{E} 5$. Precursor ions selected for fragmentation (exclude charge state 1) were put on a dynamic exclusion list for $10 \mathrm{~s}$. Additionally, the intensity threshold was calculated to be 4.0E4. The peptide match feature and the exclude isotopes feature were enabled.

\section{Data Processing protocol for analyzed peptides}

For peptide identification, the RAW-files were loaded into Proteome Discoverer (version 1.4.1.14, Thermo Scientific). All hereby created MS/MS spectra were searched using MSAmanda v1.4.14.7870 (Dorfer V. et al., J. Proteome Res. 2014 Aug 1;13(8):3679-84). The RAW-files were searched against the Swissprot sequence database, using the taxonomy human (20,171 sequences; 11,317,551 residues). The following search parameters were used: Beta-methylthiolation on cysteine was set as a fixed modification, oxidation on methionine, deamidation on asparagine and glutamine, acetylation on lysine, phosphorylation on serine, threonine and tyrosine and ubiquitination on lysine were set as variable modifications. Monoisotopic masses were searched within unrestricted protein masses for tryptic enzymatic specificity. The peptide mass tolerance was set to $\pm 5 \mathrm{ppm}$ and the fragment mass tolerance to $0.03 \mathrm{Da}$. The maximal number of missed cleavages was set to 2 . The result was filtered to $1 \%$ FDR on protein level using Percolator algorithm integrated in Thermo Proteome Discoverer. The localization of the post-translational modification sites within the peptides was performed with the 
tool ptmRS, based on the tool phosphoRS (Taus T. et al., J. Proteome Res. 2011, 10, 5354-62). Peptide areas have been quantified using in-house-developed tool APQuant (publication under review).

\section{In vitro ubiquitination assays}

A method for in vitro ubiquitination assay is described elsewhere (Asaoka et al., 2016). Briefly,

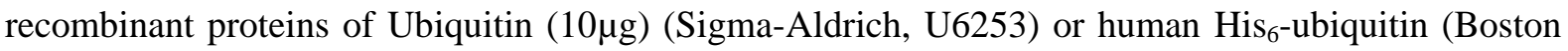

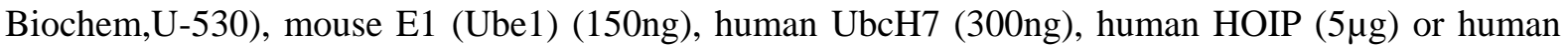

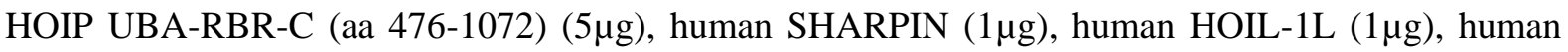
NEMO $(5 \mu \mathrm{g})$ and ATP $(2 \mathrm{mM})$ (Roche, 1051997900) were incubated in a reaction buffer consisting of 50mM HEPES (Sigma Aldrich, H4034) (pH7.5), $150 \mathrm{mM} \mathrm{NaCl}, 20 \mathrm{mM} \mathrm{MgCl}_{2}$ for the indicated times at $37^{\circ} \mathrm{C}$. Reactions were terminated by $2 \mathrm{x}$ SDS sample buffer at $96^{\circ} \mathrm{C}$ for 1 minute. Samples were subjected to SDS-PAGE and subsequent immunoblotting.

\section{In vitro deubiquitination assays (UbiCRest assays)}

Deubiquitination assays were performed as previously described (Hospenthal et al., 2015). Briefly, recombinant deubiquitinases $(3 \mu \mathrm{M}$ for vOTU (CCHFV OTU domain, aa1-183), 10 $\mu \mathrm{M}$ for human OTULIN, $3 \mu \mathrm{M}$ for human USP21 (USP domain, aa 196-565) were activated in activation buffer $(150 \mathrm{mM} \mathrm{NaCl}, 25 \mathrm{mM}$ Tris $\mathrm{pH} 7.5$, and $10 \mathrm{mM}$ DTT) for 10 minutes at room temperature. Subsequently, samples in 10x DUB reaction buffer $(500 \mathrm{mM} \mathrm{NaCl}, 500 \mathrm{mM}$ Tris $\mathrm{pH} 7.5$, and $50 \mathrm{mM}$ DTT) were incubated with activated DUB for 30 minutes at $37^{\circ} \mathrm{C}$. Reaction was terminated by $2 \mathrm{X}$ SDS sample buffer.

\section{Bioinformatics analysis}

A multiple sequence alignment of HOIP orthologues was performed with MAFFT (Katoh \& Toh, 2008) (Asaoka et al., 2016) and visualized using Jalview (Waterhouse et al., 2009).

\section{qRT-PCR}

A method is described elsewhere (Asaoka et al., 2016). $3 \times 10^{5}$ MEFs or $1 \times 10^{6}$ primary BMDMs in 6well plates were serum starved for 15 hours in 0.2\% FBS- DMEM, treated with human TNF (20ng/ml) for the indicated timepoints. Samples washed by chilled PBS two times and the total RNA was extracted using TRIzol (Life Technologies, 15596018), treated with the TURBO DNA-free kit (Invitrogen, AM1907). 500ng of RNA from MEFs or 350ng of RNA from BMDMs were reverse transcribed using oligo(dT)18 primer (New England Biolabs, \#513165) and SuperScript II Reverse Transcriptase (Invitrogen, 18064-014). The cDNA was proceeded by using a standard qPCR method with GoTaq qPCR master mix (Promega, A6002) and the CFX96 BioRad CFX 96 Real-Time PCR 
detection system. $\beta$-actin was used for normalization. Analysis was carried out using the $2^{\wedge}-\Delta \Delta C t$ method. The sequences of primers used against mouse genes are following.

IкB $\alpha$ : forward primer 5'-GCTGAGGCACTTCTGAAAGCTG-3', reverse primer 5'TGGACTGGCAGACCTACCATTG-3', ICAM: forward primer 5'AAGGAGATCACATTCACGGTG-3', reverse primer 5'-TTTGGGATGGTAGCTGGAAG-3', VCAM: forward primer 5'-CTGGGAAGCTGGAACGAAGT-3', reverse primer 5'GCCAACACTTGACCGTGAC-3', A20: forward primer 5'-AAAGGACTACAGCAGAGCCCAG3', reverse primer 5'-AGAGACATTTCCAGTCCGGTGG-3', $\beta$-actin: forward primer 5'CGGTTCCGATGCCCTGAGGCTCTT-3', CGTCACACTTCATGATGGAATTGA-3'.

\section{Caspase 8 assay}

$5 \times 10^{4}$ cells/well in a 96-well white plate (Thermoscientific, 136101) were treated by human TNF $(100 \mathrm{ng} / \mathrm{ml})$, with or without cycloheximide $(1 \mu \mathrm{g} / \mathrm{ml})$ and $\mathrm{z}-\mathrm{VAD}-\mathrm{fmk}(20 \mu \mathrm{M})$. Caspase 8 activity was measured by using the Caspase Glo 8 assay system (Promega, G8202) according to the manufacturer's protocol.

\section{Generation of C57BL/6J Hoip ${ }^{K 778 R / K 778 R}$ knockin mice}

A method is described as previously (Wang et al., 2013). Briefly, the gRNA was designed using the online tool (crispr.mit.edu). Annealed oligonucleotide with gRNA targeting sequence was cloned into px330 plasmid by a standard subcloning method (Addgene plasmid, \#42330, a gift from Feng Zhang (Cong et al., 2013)). The T7-gRNA product amplified by PCR was used as the template for in vitro transcription using the MEGAshortscript T7 kit (Invitrogen, AM1345). In vitro transcribed gRNA purified using the MEGAclear kit (Invitrogen, AM1908), Cas9 mRNA (Sigma CAS9MRNA-1EA), single strand oligonucleotide donor template containing K778R mutation, a silent mutation of the PAM sequence and a silent XmnI restriction site (ssOligo) (5' TGCATCTTGTTCCCAGCTCAGAGAGAGCCTAGACCCCGATGCATATGCCCTGTTTCACAA GAGGCTGACCGAAGCTGTTCTTATGCGAGACCCCAAGTTCTTGTGGTGCGCCCAGGTAAA CCTGACAAACAGAGTGAACT-3') were used for injection. Superovulation-induced female C57BL/6J donor mice (3-5 weeks old), treated with 5IU of pregnant mare's serum gonadotropin (PMSG) (Hölzel Diagnostika, OPPA01037) and subsequently with 5IU of human chorionic gonadotropin (hCG) (Intervet, GesmbH) were mated and zygotes were isolated in M2 media (Merck Millipore, MR-015P-D) and cultured in KSOM medium (Cosmo Bio Co., Ltd, R-B074). The microinjection mix(100ng/ $\mu \mathrm{l}$ of Cas 9 mRNA, 50ng/ $\mu \mathrm{l}$ of gRNA, 200ng/ $\mu \mathrm{l}$ of ssOligo) was microinjected into the cytosol of zygotes followed by transfer to pseudo-pregnant females. The 
genomic fragment of targeted region in $H_{o i p}{ }^{K 778 R / K 778 R}$ knockin founder mice was confirmed by Sanger sequencing.

\section{Genotyping of Hoip ${ }^{K 778 R / K 778 R}$ knockin mice}

A PCR amplified genomic DNA fragment using forward primer 5'-CGATCCTCTTGCCTCCATGT3' and reverse primer 5'-CCAGCTGTTCGCGTTCATA-3' was digested with XmnI (NEB; R0194L). Undigested and digested samples were proceeded for electrophoresis using $2 \%$ agarose gels.

\section{Mouse husbandry}

Hoip ${ }^{K 778 R / K 778 R}$ knockin C57BL/6J mice, Sharpin ${ }^{\text {cpdm/cpdm }}$ C57BL/KaLawRij (Ikeda et al., 2011), and Tnfrsfla ${ }^{\text {tmIMak }}$ TNFRp55-deficient C57BL/6J mice (JAX stock \#002818) were used in this study. All animal procedures were conducted in accordance with European, Austrian and institutional guidelines and protocols. All animal conduct was approved by local government authorities.

\section{Histopathological analysis}

A method is described elsewhere (Kumari et al., 2014). Briefly, mouse tissues of dorsal and ventral skin, lung, spleen and liver, kidney, small intestine, cecum and colon were fixed in $10 \%$ neutral buffered formalin (Sigma, HT501128), processed with a microwave hybrid tissue processor (LOGOS, Milestone Medical), embedded in paraffin, sectioned (Microm, HM 355) for the hematoxylin and eosin staining in an automated stainer (Microm HMS 740). Immunohistochemistry was performed using an automated immunostainer (Bond III, Leica). Primary antibodies used for immunohistochemistry are KRT14 (Sigma Aldrich, SAB4501657, 1:200) CASP3, cleaved (Cell Signaling, 9661, 1:100) F4.80 (Bio Rad, MCA497G, 1:100), Ly6G (Abcam, ab2557, 1:500) and secondary antibodies used are rabbit anti-rat IgG (Abcam, ab6733, 1:500), goat anti-rabbit IgG (Dako, E0432 1:500). Signal was detected with the Leica Bond Intense R Detection system. Slides were evaluated by a board certified veterinary comparative pathologist with a Zeiss Axioskop 2 MOT microscope and images were acquired with a SPOT Insight color camera (SPOT Imaging, Diagnostic Instruments, Inc.).

For the skin thickness measurement, digital images of sections stained with an KRT14 antibody were taken by the 3D Histech Pannoramic Flash III whole slide scanner, evaluated with the Pannoramic Viewer software. From each digital scene, 10 non-contiguous, representative foci were selected from a region spanning $4 \mathrm{~mm}$. In each focus, the thickness of the entire epidermis, keratin layer and squamous cell layer were measured. Measurements were tabulated and the average of ten measurements was recorded per sample.

\section{Mouse embryo analysis}


Female mice mated with male mice in breeding age were checked for copulation plugs daily. The embryos were collected at different embryo stages (E10.5, E12.5, E13.5), and fixed in 10\% neutral buffered formalin (Sigma, HT501128) for 12-24 hours at room temperature. Fixed embryos washed with PBS were imaged using a Lumar-Florescence Stereomicroscope with a color SPOT camera at 9X magnification. Embryos were processed, embedded, sectioned and stained with hematoxylin and eosin for histopathological analysis.

\section{Statistical Analysis}

Analysis was performed by the GraphPad Prism 8 software (GraphPad Software, Inc) and the mean values with standard deviation are shown. A One-way ANOVA test and Tukey's post hoc test were used. The significance and confidence level were set at 0.05 and $P$ values are indicated in each figure legends.

\section{Acknowledgements}

We thank Merle Hantsche-Grininger (EMBL, Heidelberg) and Michaela Morlock (2016 VBC summer student, currently AstraZeneca, Göteborg, Sweden) for their initial contribution to the project setups, Katrin Rittinger (Crick Institute, London) and Paul Elliott (University of Oxford, Oxford) for discussions on the structural aspect of HOIP, and all the Ikeda Lab members for constructive discussions and suggestions on the project, as well as the team work. We also thank Anna Szydłowska and Kikue Tachibana (IMBA, Vienna) for the technical advice on CRISPR-Cas9-based knockin mouse generation, Adrian Ting (Icahn School of Medicine at Mount Sinai, New York) for an advice on ear-derived fibroblast isolation, Richard Imre (Protein Chemistry, Vienna) for the Mass spectrometry data analysis, the IMP-IMBA core facilities of transgenic service, comparative medicine, molecular biology service, biooptics, and VBCF facilities, ProTech and Histo Pathology for their technical assistance. Research in Ikeda Lab is supported by ERC Consolidator Grant (LUbi, 614711), FWF stand-alone grant (P 2550 8) and Austrian Academy of Sciences. We also thank Angela Andersen from the Life Science Editors for editing the manuscript.

\section{Author contributions}

L.M.F. preformed most of the experiments, analyzed data, made figures and contributed in writing the manuscript. L.D. expressed and purified recombinant proteins required for in vitro assays, A.S. analyzed amino acid sequences of HOIP orthologues and made alignment, K.M. contributed to the mass spectrometry analysis, and A.K. performed histological analysis. F.I. planned and conducted the project, analyzed data, made figures, and wrote the manuscript. 


\section{Conflict of interest}

None.

\section{References}

Akutsu M, Ye Y, Virdee S, Chin JW, Komander D (2011) Molecular basis for ubiquitin and ISG15 cross-reactivity in viral ovarian tumor domains. Proceedings of the National Academy of Sciences 108: $2228-2233$

Ang RL, Ting AT (2018) Detection of RIPK1 in the FADD-Containing Death Inducing Signaling Complex (DISC) During Necroptosis. In Programmed Necrosis: Methods and Protocols, Ting AT (ed) pp 101-107. New York, NY: Springer New York

Asaoka T, Almagro J, Ehrhardt C, Tsai I, Schleiffer A, Deszcz L, Junttila S, Ringrose L, Mechtler K, Kavirayani A, Gyenesei A, Hofmann K, Duchek P, Rittinger K, Ikeda F (2016) Linear ubiquitination by LUBEL has a role in Drosophila heat stress response. EMBO reports 17: 1624-1640

Asaoka T, Ikeda F (2015) New Insights into the Role of Ubiquitin Networks in the Regulation of Antiapoptosis Pathways. Int Rev Cell Mol Biol 318: 121-58

Boisson B, Laplantine E, Dobbs K, Cobat A, Tarantino N, Hazen M, Lidov HG, Hopkins G, Du L, Belkadi A, Chrabieh M, Itan Y, Picard C, Fournet JC, Eibel H, Tsitsikov E, Pai SY, Abel L, Al-Herz W, Casanova JL et al. (2015) Human HOIP and LUBAC deficiency underlies autoinflammation, immunodeficiency, amylopectinosis, and lymphangiectasia. The Journal of experimental medicine 212: 939-51

Boisson B, Laplantine E, Prando C, Giliani S, Israelsson E, Xu Z, Abhyankar A, Israel L, TrevejoNunez G, Bogunovic D, Cepika AM, MacDuff D, Chrabieh M, Hubeau M, Bajolle F, Debre M, Mazzolari E, Vairo D, Agou F, Virgin HW et al. (2012) Immunodeficiency, autoinflammation and amylopectinosis in humans with inherited HOIL-1 and LUBAC deficiency. Nature immunology 13: $1178-86$

Cong L, Ran FA, Cox D, Lin S, Barretto R, Habib N, Hsu PD, Wu X, Jiang W, Marraffini LA, Zhang F (2013) Multiplex genome engineering using CRISPR/Cas systems. Science (New York, NY) 339: $819-23$

Damgaard RB, Walker JA, Marco-Casanova P, Morgan NV, Titheradge HL, Elliott PR, McHale D, Maher ER, McKenzie ANJ, Komander D (2016) The Deubiquitinase OTULIN Is an Essential Negative Regulator of Inflammation and Autoimmunity. Cell 166: 1215-1230 e20

Dove KK, Klevit RE (2017) RING-Between-RING E3 Ligases: Emerging Themes amid the Variations. Journal of molecular biology 429: 3363-3375

Draber P, Kupka S, Reichert M, Draberova H, Lafont E, de Miguel D, Spilgies L, Surinova S, Taraborrelli L, Hartwig T, Rieser E, Martino L, Rittinger K, Walczak H (2015) LUBAC-Recruited 
CYLD and A20 Regulate Gene Activation and Cell Death by Exerting Opposing Effects on Linear Ubiquitin in Signaling Complexes. Cell reports 13: 2258-72

Elliott PR, Leske D, Hrdinka M, Bagola K, Fiil BK, McLaughlin SH, Wagstaff J, Volkmar N, Christianson JC, Kessler BM, Freund SM, Komander D, Gyrd-Hansen M (2016) SPATA2 Links CYLD to LUBAC, Activates CYLD, and Controls LUBAC Signaling. Molecular cell 63: 990-1005

Elliott PR, Nielsen SV, Marco-Casanova P, Fiil BK, Keusekotten K, Mailand N, Freund SM, GyrdHansen M, Komander D (2014) Molecular basis and regulation of OTULIN-LUBAC interaction. Molecular cell 54: 335-48

Emmerich CH, Ordureau A, Strickson S, Arthur JS, Pedrioli PG, Komander D, Cohen P (2013) Activation of the canonical IKK complex by K63/M1-linked hybrid ubiquitin chains. Proceedings of the National Academy of Sciences of the United States of America 110: 15247-52

Fiil BK, Damgaard RB, Wagner SA, Keusekotten K, Fritsch M, Bekker-Jensen S, Mailand N, Choudhary C, Komander D, Gyrd-Hansen M (2013) OTULIN restricts Met1-linked ubiquitination to control innate immune signaling. Molecular cell 50: 818-830

Gerlach B, Cordier SM, Schmukle AC, Emmerich CH, Rieser E, Haas TL, Webb AI, Rickard JA, Anderton H, Wong WW, Nachbur U, Gangoda L, Warnken U, Purcell AW, Silke J, Walczak H (2011) Linear ubiquitination prevents inflammation and regulates immune signalling. Nature 471: $591-6$

Haas TL, Emmerich CH, Gerlach B, Schmukle AC, Cordier SM, Rieser E, Feltham R, Vince J, Warnken U, Wenger T, Koschny R, Komander D, Silke J, Walczak H (2009) Recruitment of the linear ubiquitin chain assembly complex stabilizes the TNF-R1 signaling complex and is required for TNF-mediated gene induction. Molecular cell 36: 831-44

Heger K, Wickliffe KE, Ndoja A, Zhang J, Murthy A, Dugger DL, Maltzman A, de Sousa EMF, Hung J, Zeng Y, Verschueren E, Kirkpatrick DS, Vucic D, Lee WP, Roose-Girma M, Newman RJ, Warming S, Hsiao YC, Komuves LG, Webster JD et al. (2018) OTULIN limits cell death and inflammation by deubiquitinating LUBAC. Nature 559: 120-124

Helmut B, Hildburg B, J. GH (1987) Improved silver staining of plant proteins, RNA and DNA in polyacrylamide gels. ELECTROPHORESIS 8: 93-99

Hospenthal MK, Mevissen TET, Komander D (2015) Deubiquitinase-based analysis of ubiquitin chain architecture using Ubiquitin Chain Restriction (UbiCRest). Nature Protocols 10: 349

Hrdinka M, Fiil BK, Zucca M, Leske D, Bagola K, Yabal M, Elliott PR, Damgaard RB, Komander D, Jost PJ, Gyrd-Hansen M (2016) CYLD Limits Lys63- and Met1-Linked Ubiquitin at Receptor Complexes to Regulate Innate Immune Signaling. Cell reports 14: 2846-58

Hrdinka M, Gyrd-Hansen M (2017) The Met1-Linked Ubiquitin Machinery: Emerging Themes of (De)regulation. Molecular cell 68: 265-280

Ikeda F (2015) Linear ubiquitination signals in adaptive immune responses. Immunological reviews 266: $222-36$ 
Ikeda F, Deribe YL, Skånland SS, Stieglitz B, Grabbe C, Franz-Wachtel M, van Wijk SJL, Goswami P, Nagy V, Terzic J, Tokunaga F, Androulidaki A, Nakagawa T, Pasparakis M, Iwai K, Sundberg JP, Schaefer L, Rittinger K, Macek B, Dikic I (2011) SHARPIN forms a linear ubiquitin ligase complex regulating NF-кB activity and apoptosis. Nature 471: 637

Justus SJ, Ting AT (2015) Cloaked in ubiquitin, a killer hides in plain sight: the molecular regulation of RIPK1. Immunological reviews 266: 145-60

Katoh K, Toh H (2008) Recent developments in the MAFFT multiple sequence alignment program. Brief Bioinform 9: 286-98

Keusekotten K, Elliott PR, Glockner L, Fiil BK, Damgaard RB, Kulathu Y, Wauer T, Hospenthal MK, Gyrd-Hansen M, Krappmann D, Hofmann K, Komander D (2013) OTULIN antagonizes LUBAC signaling by specifically hydrolyzing Met1-linked polyubiquitin. Cell 153: 1312-26

Kirisako T, Kamei K, Murata S, Kato M, Fukumoto H, Kanie M, Sano S, Tokunaga F, Tanaka K, Iwai K (2006) A ubiquitin ligase complex assembles linear polyubiquitin chains. The EMBO journal 25: $4877-87$

Kumari S, Redouane Y, Lopez-Mosqueda J, Shiraishi R, Romanowska M, Lutzmayer S, Kuiper J, Martinez C, Dikic I, Pasparakis M, Ikeda F (2014) Sharpin prevents skin inflammation by inhibiting TNFR1-induced keratinocyte apoptosis. eLife 3: e03422

Kupka S, De Miguel D, Draber P, Martino L, Surinova S, Rittinger K, Walczak H (2016) SPATA2Mediated Binding of CYLD to HOIP Enables CYLD Recruitment to Signaling Complexes. Cell reports 16: 2271-80

Lamkanfi M, Festjens N, Declercq W, Vanden Berghe T, Vandenabeele P (2007) Caspases in cell survival, proliferation and differentiation. Cell Death Differ 14: 44-55

Lechtenberg BC, Rajput A, Sanishvili R, Dobaczewska MK, Ware CF, Mace PD, Riedl SJ (2016) Structure of a HOIP/E2 ubiquitin complex reveals RBR E3 ligase mechanism and regulation. Nature 529: $546-50$

Meier P, Morris O, Broemer M (2015) Ubiquitin-Mediated Regulation of Cell Death, Inflammation, and Defense of Homeostasis. Curr Top Dev Biol 114: 209-39

Peltzer N, Darding M, Montinaro A, Draber P, Draberova H, Kupka S, Rieser E, Fisher A, Hutchinson C, Taraborrelli L, Hartwig T, Lafont E, Haas TL, Shimizu Y, Boiers C, Sarr A, Rickard J, Alvarez-Diaz S, Ashworth MT, Beal A et al. (2018) LUBAC is essential for embryogenesis by preventing cell death and enabling haematopoiesis. Nature 557: 112-117

Peltzer N, Darding M, Walczak H (2016) Holding RIPK1 on the Ubiquitin Leash in TNFR1 Signaling. Trends Cell Biol 26: 445-461

Peltzer N, Rieser E, Taraborrelli L, Draber P, Darding M, Pernaute B, Shimizu Y, Sarr A, Draberova H, Montinaro A, Martinez-Barbera JP, Silke J, Rodriguez TA, Walczak H (2014) HOIP deficiency causes embryonic lethality by aberrant TNFR1-mediated endothelial cell death. Cell reports 9: 153165 
Peltzer N, Walczak H (2019) Cell Death and Inflammation - A Vital but Dangerous Liaison. Trends Immunol 40: 387-402

Rahighi S, Ikeda F, Kawasaki M, Akutsu M, Suzuki N, Kato R, Kensche T, Uejima T, Bloor S, Komander D, Randow F, Wakatsuki S, Dikic I (2009) Specific recognition of linear ubiquitin chains by NEMO is important for NF-kappaB activation. Cell 136: 1098-109

Reiley WW, Zhang M, Jin W, Losiewicz M, Donohue KB, Norbury CC, Sun SC (2006) Regulation of T cell development by the deubiquitinating enzyme CYLD. Nature immunology 7: 411-7

Rickard JA, Anderton H, Etemadi N, Nachbur U, Darding M, Peltzer N, Lalaoui N, Lawlor KE, Vanyai H, Hall C, Bankovacki A, Gangoda L, Wong WW, Corbin J, Huang C, Mocarski ES, Murphy JM, Alexander WS, Voss AK, Vaux DL et al. (2014) TNFR1-dependent cell death drives inflammation in Sharpin-deficient mice. Elife 3

Rittinger K, Ikeda F (2017) Linear ubiquitin chains: enzymes, mechanisms and biology. Open Biol 7 Sasaki K, Iwai K (2015) Roles of linear ubiquitinylation, a crucial regulator of NF-kappaB and cell death, in the immune system. Immunological reviews 266: 175-89

Sasaki Y, Fujita H, Nakai M, Iwai K (2015) Immunoblot analysis of linear polyubiquitination of NEMO. Methods in molecular biology (Clifton, NJ) 1280: 297-309

Schaeffer V, Akutsu M, Olma MH, Gomes LC, Kawasaki M, Dikic I (2014) Binding of OTULIN to the PUB domain of HOIP controls NF-kappaB signaling. Molecular cell 54: 349-61

Schneider P, Bodmer JL, Holler N, Mattmann C, Scuderi P, Terskikh A, Peitsch MC, Tschopp J (1997) Characterization of Fas (Apo-1, CD95)-Fas ligand interaction. The Journal of biological chemistry 272: 18827-33

Seymour RE, Hasham MG, Cox GA, Shultz LD, Hogenesch H, Roopenian DC, Sundberg JP (2007) Spontaneous mutations in the mouse Sharpin gene result in multiorgan inflammation, immune system dysregulation and dermatitis. Genes and immunity 8: 416-21

Smit JJ, Monteferrario D, Noordermeer SM, van Dijk WJ, van der Reijden BA, Sixma TK (2012) The E3 ligase HOIP specifies linear ubiquitin chain assembly through its RING-IBR-RING domain and the unique LDD extension. The EMBO journal 31: 3833-44

Smit JJ, Sixma TK (2014) RBR E3-ligases at work. EMBO Rep 15: 142-54

Smit JJ, van Dijk WJ, El Atmioui D, Merkx R, Ovaa H, Sixma TK (2013) Target specificity of the E3 ligase LUBAC for ubiquitin and NEMO relies on different minimal requirements. The Journal of biological chemistry 288: 31728-37

Stieglitz B, Morris-Davies AC, Koliopoulos MG, Christodoulou E, Rittinger K (2012) LUBAC synthesizes linear ubiquitin chains via a thioester intermediate. EMBO reports 13: 840-846

Takiuchi T, Nakagawa T, Tamiya H, Fujita H, Sasaki Y, Saeki Y, Takeda H, Sawasaki T, Buchberger A, Kimura T, Iwai K (2014) Suppression of LUBAC-mediated linear ubiquitination by a specific interaction between LUBAC and the deubiquitinases CYLD and OTULIN. Genes to cells : devoted to molecular \& cellular mechanisms 19: 254-72 
Tokunaga F, Nakagawa T, Nakahara M, Saeki Y, Taniguchi M, Sakata S, Tanaka K, Nakano H, Iwai K (2011) SHARPIN is a component of the NF-kappaB-activating linear ubiquitin chain assembly complex. Nature 471: 633-6

Tokunaga F, Sakata S, Saeki Y, Satomi Y, Kirisako T, Kamei K, Nakagawa T, Kato M, Murata S, Yamaoka S, Yamamoto M, Akira S, Takao T, Tanaka K, Iwai K (2009) Involvement of linear polyubiquitylation of NEMO in NF-kappaB activation. Nat Cell Biol 11: 123-32

Wagner SA, Satpathy S, Beli P, Choudhary C (2016) SPATA2 links CYLD to the TNF-alpha receptor signaling complex and modulates the receptor signaling outcomes. The EMBO journal 35: 1868-84

Walczak H (2011) TNF and ubiquitin at the crossroads of gene activation, cell death, inflammation, and cancer. Immunological reviews 244: 9-28

Walden H, Rittinger K (2018) RBR ligase-mediated ubiquitin transfer: a tale with many twists and turns. Nature structural \& molecular biology 25: 440-445

Wang H, Yang H, Shivalila CS, Dawlaty MM, Cheng AW, Zhang F, Jaenisch R (2013) One-step generation of mice carrying mutations in multiple genes by CRISPR/Cas-mediated genome engineering. Cell 153: 910-8

Waterhouse AM, Procter JB, Martin DM, Clamp M, Barton GJ (2009) Jalview Version 2--a multiple sequence alignment editor and analysis workbench. Bioinformatics (Oxford, England) 25: 1189-91

Witt A, Vucic D (2017) Diverse ubiquitin linkages regulate RIP kinases-mediated inflammatory and cell death signaling. Cell Death Differ 24: 1160-1171

Ye Y, Akutsu M, Reyes-Turcu F, Enchev RI, Wilkinson KD, Komander D (2011) Polyubiquitin binding and cross-reactivity in the USP domain deubiquitinase USP21. EMBO Rep 12: 350-7

Zhang J, Stirling B, Temmerman ST, Ma CA, Fuss IJ, Derry JM, Jain A (2006) Impaired regulation of NF-kappaB and increased susceptibility to colitis-associated tumorigenesis in CYLD-deficient mice.

The Journal of clinical investigation 116: 3042-9

\section{Figure legends}

Figure 1 - Human HOIP is ubiquitinated at $\mathrm{K784}$ and regulates NF-кB.

A. A scheme of procedures for UbiCRest-based assays to analyze HOIP-modification with ubiquitin chains. Total cell extracts from HEK293T cells transiently expressing Myc-HOIP and Myc-OTULIN C129A, a catalytic inactive mutant, subjected to GST-linear-TUBE pulldown followed by UbiCRest assays using recombinant deubiquitinases (vOTU, OTULIN and USP21).

B. UbiCRest assays to evaluate ubiquitin chain types on HOIP examined by immunoblotting. Immunoblotting of samples using antibodies as indicated. Ponceau S staining used for monitoring GST-liner-TUBE input. Representative data shown from three independent experiments. 
C. Mass spectrometry spectra corresponding to a peptide containing HOIP-K784 with double Gly $(114+\mathrm{K})$.

D. Domains of human HOIP and identified ubiquitination sites at K454, K458, K735 and K784.

E. Multiple sequence alignment of different HOIP orthologues illustrating the position K735 and K784 according to the ClustalX colour scheme. Sequences were retrieved from the NCBI protein database with the following accessions: Homo sapiens (NP_060469.4), Canis lupus (XP_005623312.1), Mus musculus (NP_919327.2), Monodelphis domestica (XP_007479924.1), Xenopus laevis (NP_001090429.1), Alligator mississippiensis (XP_006259801.1), Takifugu rubripes (XP_003968217.2) and Drosophila melanogaster (NP_723214.2).

F. Co-immunoprecipitation analysis of the HOIP K784R mutant with SHARPIN and HOIL-1L using total cell extracts of HEK293T cells transiently expressing Myc-HOIP wildtype (WT), Myc-HOIPK784R, or Myc-HOIP-C885A (a catalytic inactive mutant) with HOIL-1L-HA and Flag-SHARPIN. Anti-Vinculin antibody used to monitor the loading. Representative data shown from three independent experiments.

G. Luciferase-based NF- $\kappa \mathrm{B}$ gene reporter assays using Myc -HOIP wildtype (WT), a catalytic inactive mutant C885A, ubiquitination site mutants of K454R, K458R, K735R, K784R co-transfected with HOIL-1L-HA and Flag-SHARPIN. Luciferase signal was normalized to an internal Renilla control signal.

Data information: In $\mathrm{G}$, data are presented as mean $\pm \mathrm{SD}$. ${ }^{* *} \mathrm{p} \leq 0.01,{ }^{* * * *} \mathrm{p} \leq 0.0001$ (ANOVA). $\mathrm{n}=4$

Figure 2 - The human HOIP K784R mutant as a part of the LUBAC generates linear ubiquitin chains and ubiquitinates its substrate NEMO in vitro and in cells.

A. In vitro ubiquitination assays for the indicated times using the recombinant proteins of ubiquitin (Ub), E1, E2 (UbcH7), HOIP (WT, K784R or C885A mutant), HOIL-1L, SHARPIN and NEMO. Immunoblotting of Linear ubiquitin chains, NEMO, HOIP, HOIL-1L and SHARPIN detected by using antibodies as indicated. Representative data from three independent experiments.

B. Immunoblotting to detect ubiquitination of NEMO in HEK293T cells transiently expressing FlagNEMO, GFP-SHARPIN, and HOIL-1L-HA with Myc-HOIP wildtype (WT), Myc-HOIP K784R or Myc-HOIP C885A. Total cell lysates in denaturing conditions subjected to SDS-PAGE followed up by immunoblotting using antibodies as indicated. Anti-Vinculin antibody to monitor loading. Representative data from three independent experiments.

Figure 3 -No obvious developmental defect in Hoip ${ }^{K 778 R / K 778 R}$ knockin mice is observed while TNF-responses are suppressed in Hoip ${ }^{\text {K778R/K778R }}$ cells. 
A. Numbers of weaned mice of the indicated genotypes from Hoip ${ }^{+/ K 778 R} ;$ Sharpin $^{+/ c p d m}$ crosses. $^{2}$

B. A gross appearance image of Hoip $^{+/+}$and Hoip ${ }^{K 778 R / K 778 R}$ male mice at 6-week old.

C. Immunoblotting to detect TNF-induced degradation and phosphorylation of I $\kappa \mathrm{B}-\alpha$ in immortalized Hoip $^{+/+}$and Hoip ${ }^{K 778 R / K 778 R}$ MEFs treated with human TNF $(20 \mathrm{ng} / \mathrm{ml})$ for the indicated times. AntiVinculin antibody for monitoring loading amount. Representative data from three independent experiments.

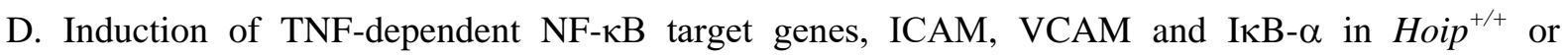
Hoip ${ }^{K 778 R / K 778 R}$ immortalized MEFs determined by qRT-PCR. RNA extraction and cDNA synthesis from MEFs treated with hTNF $(20 \mathrm{ng} / \mathrm{ml})$ for the indicated time subjected to examine transcripts of ICAM, VCAM and IкB- $\alpha$. Normalization to $\beta$-actin.

E. Immunoblotting of TNF-immunoprecipitation to examine TNFR complex I formation in immortalized Hoip $^{+/+}$or Hoip ${ }^{K 778 R / K 778 R}$ MEFs treated with Flag-hTNF $(1 \mu \mathrm{g} / \mathrm{ml})$ for the indicated time using indicated antibodies. Representative data from three independent experiments.

F. TNF-dependent induction of cleavage of PARP and Caspase 3 in primary Hoip ${ }^{+/+}$or Hoip ${ }^{K 778 R / K 778 R}$ MEFs determined by immunoblotting. Total cell extracts of MEFs treated with hTNF (100ng/ml) and CHX $(1 \mu \mathrm{g} / \mathrm{ml})$ for the indicated times subjected to SDS-PAGE followed by immunoblotting using antibodies as indicated. Anti- $\alpha$-Tubulin antibody used to monitor loading amount. Representative data of two independent experiments.

G. TNF-induced Caspase 8 activity in Hoip $^{+/+}$or Hoip ${ }^{K 778 R / K 778 R}$ immortalized MEFs treated with hTNF $(100 \mathrm{ng} / \mathrm{ml})$ with or without Cycloheximide (CHX) $(1 \mu \mathrm{g} / \mathrm{ml})$ or z-VAD $(20 \mu \mathrm{M})$.

H TNF-receptor complex II formation in $\mathrm{Hoip}^{+/+}$or Hoip ${ }^{K 778 R / K 778 R}$ immortalized MEFs. Total cell extracts of MEFs treated with hTNF $(100 \mathrm{ng} / \mathrm{ml}), \mathrm{CHX}(1 \mu \mathrm{g} / \mathrm{ml})$ and $\mathrm{zVAD}(25 \mu \mathrm{M})$ for the indicated timeimmunoprecipitated using an anti-FADD antibody. Recruitment of RIPK1, HOIP and SHARPIN monitored by immunoblotting. Representative of two independent experiments.

Data information: In ( $\mathrm{D}$ and $\mathrm{G})$, data are presented as mean $\pm \mathrm{SD} .{ }^{*} \mathrm{p} \leq 0.01,{ }^{* * *} \mathrm{p} \leq 0.001$, $* * * * \mathrm{p} \leq 0.0001$ (ANOVA, $\mathrm{n}=3$ in $\mathrm{D}$ and $\mathrm{n}=4$ in $\mathrm{G}$ ).

\section{Figure 4 - SHARPIN-deficiency leads Hoip $^{K 778 R / K 778 R}$ mice to embryonic lethality, which is rescued by TNFR1 knockout.}

A. Numbers of weaned mice of the indicated genotypes from crosses of Hoip $^{+/ K 778 R}$; Sharpin ${ }^{+/ c p d m}$ mice.

B. Number of the embryos of the indicated genotype at E12.5 and E13.5 from crosses of Hoip ${ }^{K 778 R / K 778 R}$; Sharpin ${ }^{+/ c p d m}$ mice. 
C. Gross appearance images of Hoip ${ }^{\text {K778R/K778R }}$; Sharpin ${ }^{+/+}$, Hoip $^{\text {K778R/K778R }}$; Sharpin ${ }^{+/ c p d m}$ and Hoip ${ }^{K 778 R / K 778 R}$; Sharpin ${ }^{\text {cpdm/cpdm }}$ embryos at E13.5. Representative pictures from 7 embryos each. Scale bars : $1 \mathrm{~mm}$

D. Gross appearance images of $\mathrm{Hoip}^{+/ K 778 R}$;Sharpin ${ }^{\text {cpdm/cpdm }} ; \mathrm{Tnfrl}^{+/-}$and Hoip ${ }^{K 778 R /+}$; Sharpin ${ }^{\text {cpdm/cpdm }}$;

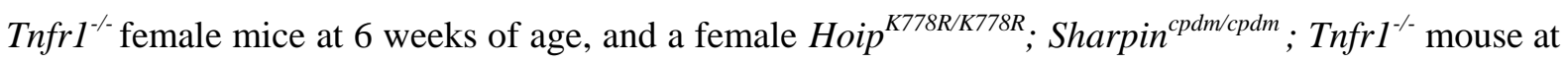
8 weeks of age.

E. H\&E staining and Keratin 14 (KRT14) immunostaining of dorsal skin sections of the indicated genotypes at 4-week or 8-week old of age. Scale bars: 50um.

Figure 5 - SHARPIN-deficiency in Hoip $^{+/ K 778 R}$ heterozygous mice leads to early onset of skin inflammation accompanied with apoptosis induction.

A. Gross appearance images of mice of the indicated genotypes (male mice at 4-week old). Scale bars: $10 \mathrm{~mm}$.

B. Immunostaining of dorsal skin sections (H\&E, Keratin 14 (KRT14), Ly6G, F4/80 and Cleaved Caspase 3) of mice with the indicated genotypes. Scale bars: $50 \mu \mathrm{m}$.

C-E. Measurements of dorsal skin sections (Total epidermis skin thickness, Keratin layer thickness and Squamous cell layer thickness) obtained from male mice of the indicated genotypes. Each dot on the scatter dot plot represents one focus point of the measurement. $\left(\mathrm{N}=20,20,30,40,40\right.$ for Hoip $^{+/+}$; Sharpin $^{+/+}$, Hoip $^{\text {K778R/K778R }} ;$ Sharpin $^{+/+}$, Hoip $^{+/ K 778 R} ;$ Sharpin $^{+/ \text {cpdm }}$, Hoip $^{+/+} ;$Sharpin $^{\text {cpdm/cpdm }}$, Hoip $^{+/ K 778 R}$; Sharpin ${ }^{\text {cpdm/cpdm }}$, respectively.)

F. Immunoblotting to examine TNF-induced degradation and phosphorylation of IKB- $\alpha$ in immortalized MEFs of the indicated genotypes using total cell extracts of MEFs treated with hTNF $(20 \mathrm{ng} / \mathrm{ml})$ for the indicated times. Representative of three independent experiments.

G. Immunoblotting of TNF-induced cleavage of PARP and caspase 3 in immortalized MEFs of the indicated genotypes using total cell extracts of MEFs treated with hTNF $(100 \mathrm{ng} / \mathrm{ml})$ with or without CHX $(1 \mu \mathrm{g} / \mathrm{ml})$ for indicated times. Representative of three independent experiments.

H. TNF-induced Caspase 8 activity in immortalized MEFs of indicated genotype. Luminol-dependent activity of Caspase 8 in immortalized MEFs treated with hTNF $(100 \mathrm{ng} / \mathrm{ml})$ with or without CHX $(1 \mu \mathrm{g} / \mathrm{ml})$ or z-VAD $(20 \mu \mathrm{M})$.

Data information: In $(\mathrm{C}-\mathrm{E}$ and $\mathrm{H})$, data are presented as mean $\pm \mathrm{SD}$. $\left(\mathrm{n}=4\right.$ for $\mathrm{H},{ }^{* * *} \mathrm{p} \leq 0.001$, $* * * * \mathrm{p} \leq 0.0001$, ANOVA).

Figure 6 - A proposed model of HOIP-site specific ubiquitination in the regulation of the TNF signaling cascades. 
A working model describing a role of site-specific ubiquitination of HOIP in the regulation of the TNF-induced NF-KB and apoptosis pathways based on this study. Schematics of simplified TNF signaling in wild type cells (WT, left panel) and HOIP-K784R cells (right panel) are shown. Upon TNF-binding to TNF receptor 1, complex I formation, which includes RIPK1 and LUBAC components (HOIP, HOIL-1L and SHARPIN) is formed. In this signaling cascade, LUBAC ubiquitinates NEMO and RIPK1. Site specific ubiquitination of HOIP at K784 plays a role in inducing TNF-dependent NF- $\kappa \mathrm{B}$ target genes and in inhibition of apoptosis by inhibiting RIPK1 recruitment into TNF receptor complex II. 
Figure 1 bioRxiv preprint doi: https://doi.org/10.1101/742544; this version posted August 21, 2019. The copyright holder for this preprint (which was A not certified by peer review) is the author/funder, who has. granted biokusie a license to display the preprint in perpetuity. It is made

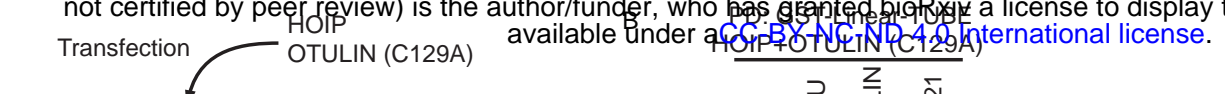

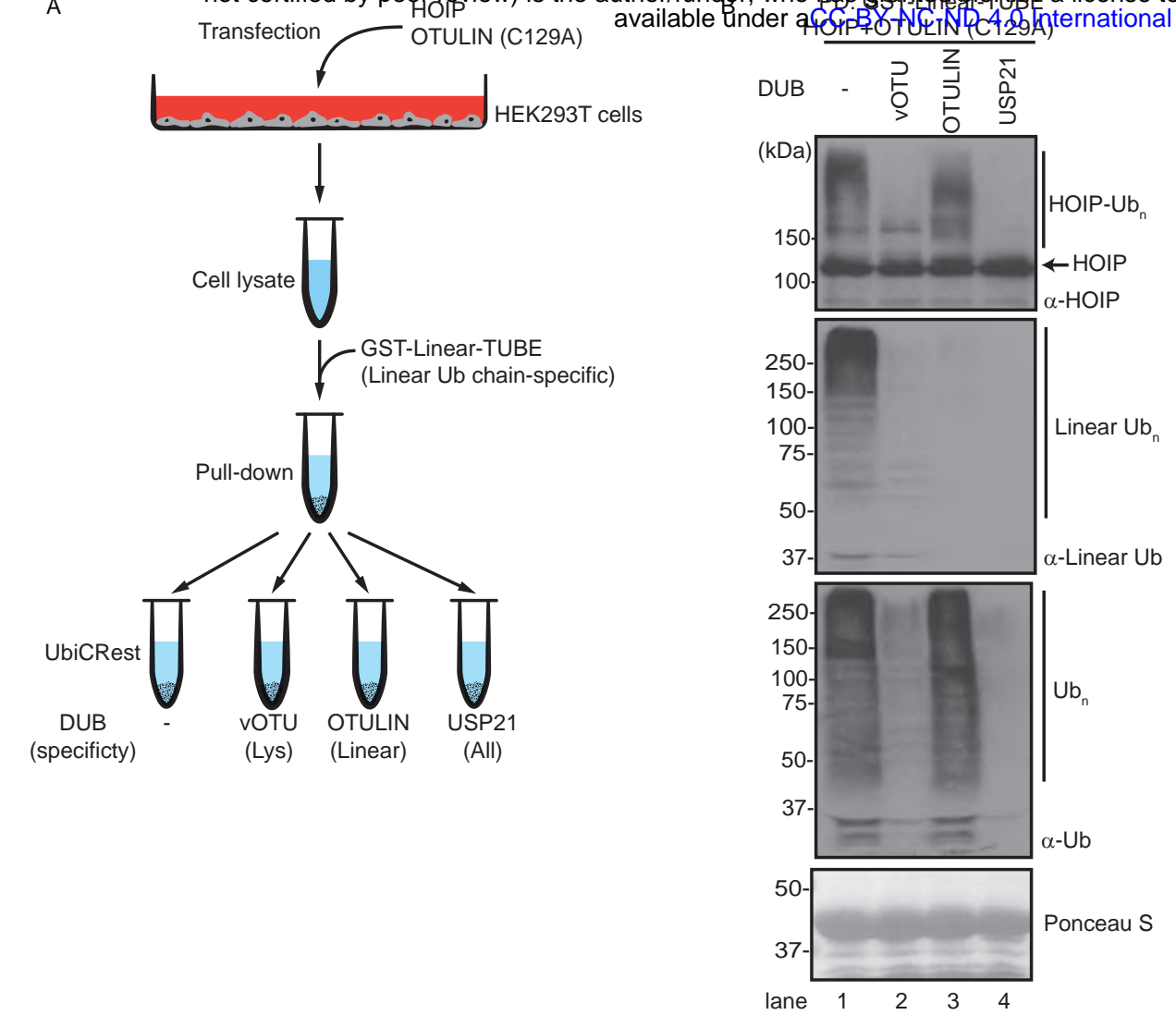

C

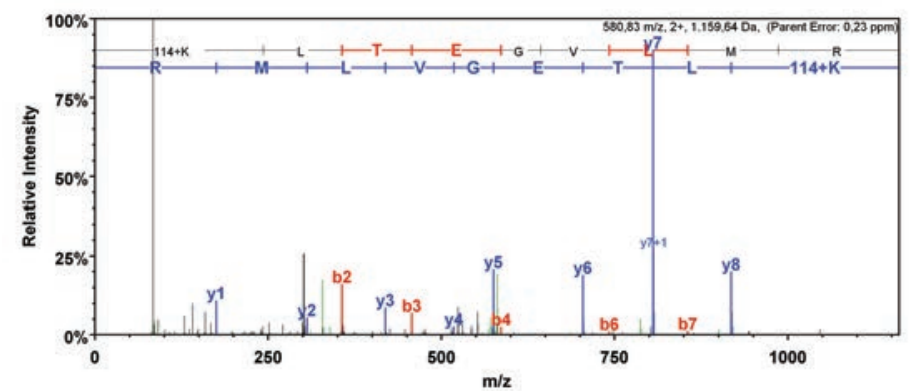

D
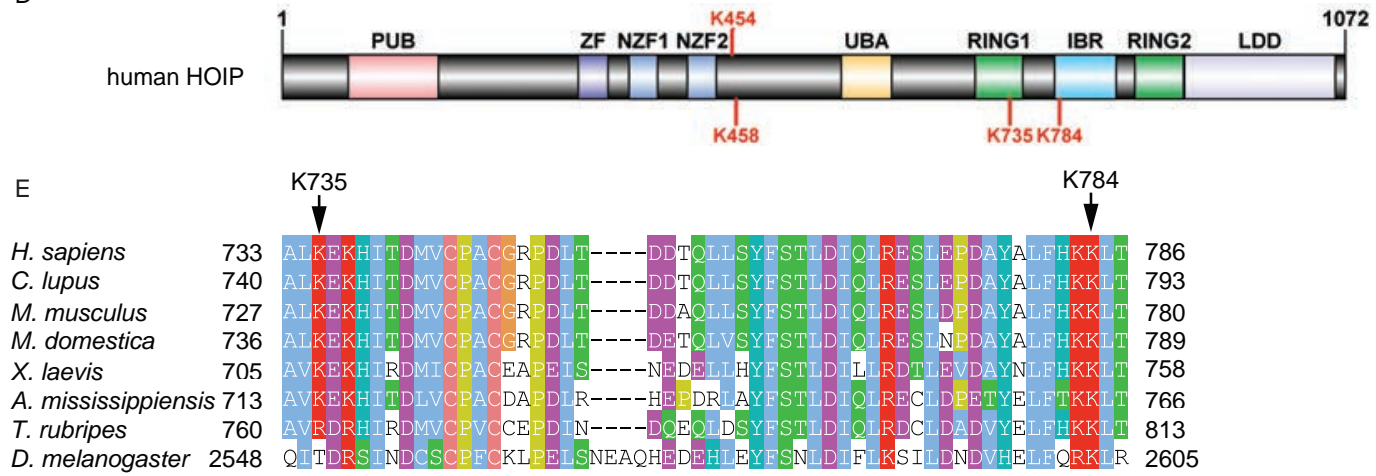

F

SHARPIN, HOIL-1L - ++++

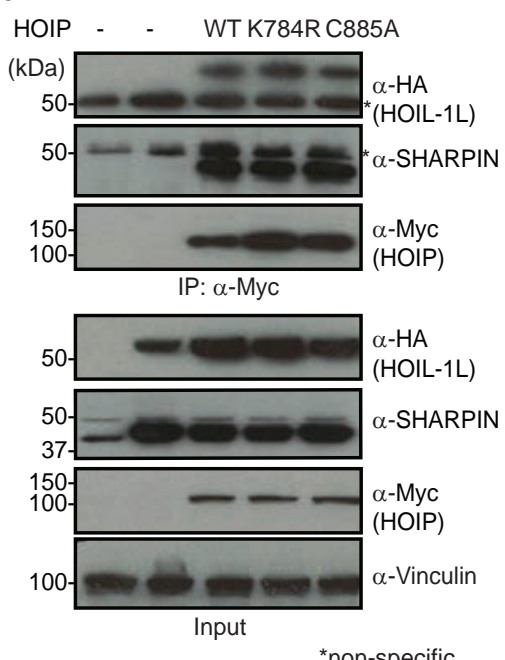

G

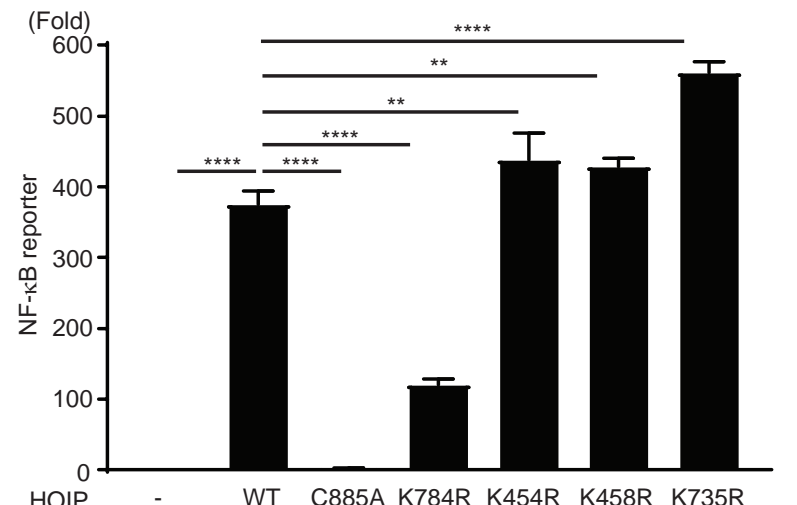

HOIP SHARPIN, HOIL-1L 
Figure 2 bioRxiv preprint doi: https://doi.org/10.1101/742544; this version posted August 21, 2019. The copyright holder for this preprint (which was not certified by peer review) is the author/funder, who has granted bioRxiv a license to display the preprint in perpetuity. It is made Ub, E1, E2 (UbcH7), HOIL-1L, SHARPIN

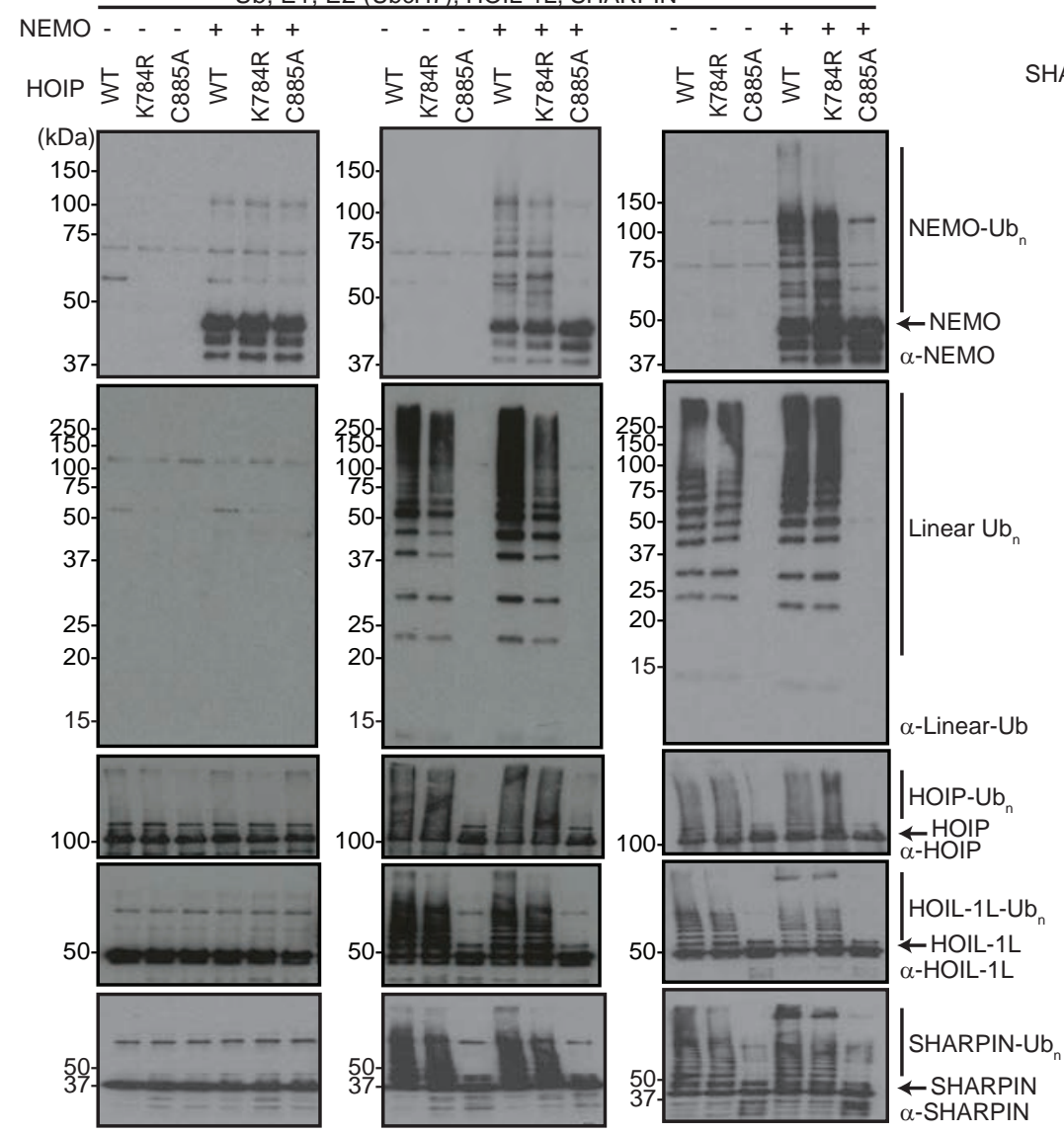

$\mathrm{Ub}, \mathrm{NEMO}-\quad+\quad+++$

SHARPIN, HOIL-1L - - + + +

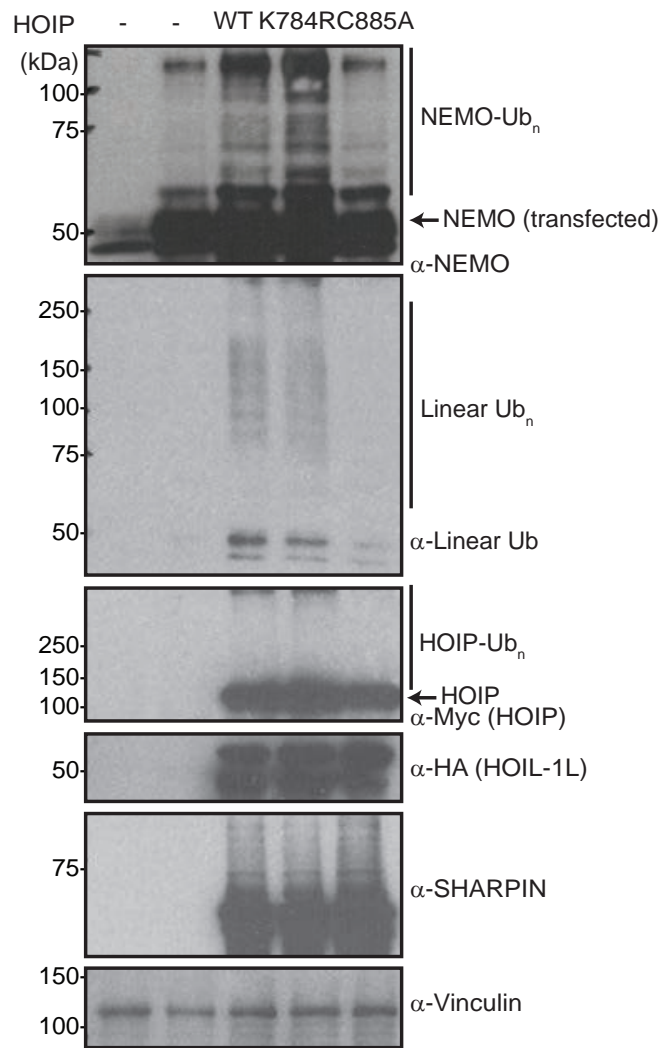


Figure 3 bioRxiv preprint doi: https://doi.org/10.1101/742544; this version posted August 21, 2019. The copyright holder for this preprint (which was A not certified by peer review) is the author/funder, whothets granted bioRxiv a license to display the preprint in perpetuity. It is made

\begin{tabular}{c|ccc|c} 
& \multicolumn{3}{|c}{ Hoip } & \\
\cline { 2 - 4 } genotype & $+/+$ & $+/ K 778 R$ & $K 778 R / K 778 R$ & Total \\
\hline weaned & 33 & 58 & 23 & \multirow{2}{*}{114} \\
(expected) & $(28.5)$ & $(57)$ & $(28.5)$ &
\end{tabular}

B

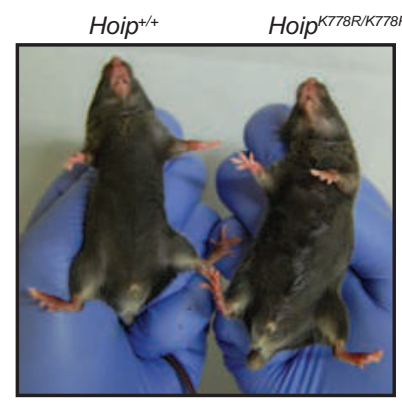

D (Fold)

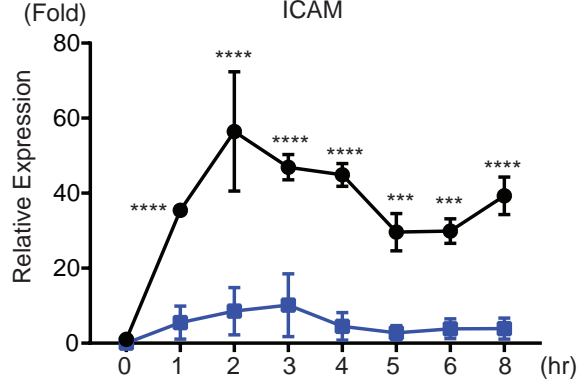

E
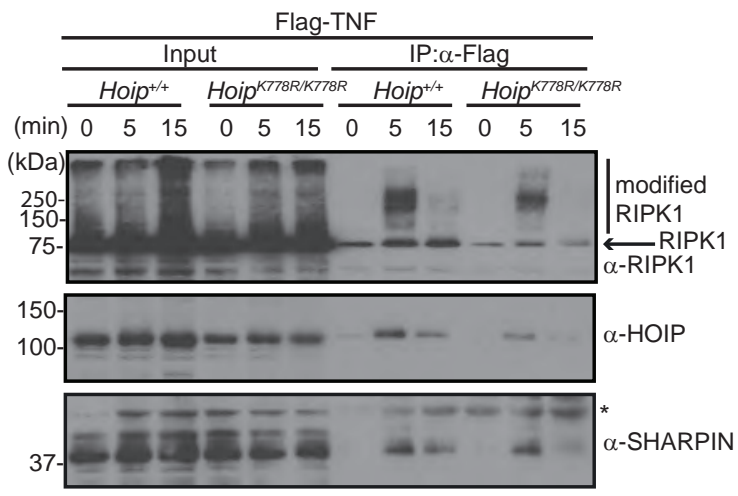

$\alpha$-SHARPIN

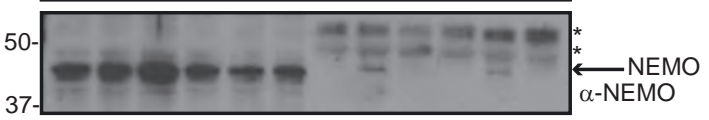

*non-specific

G

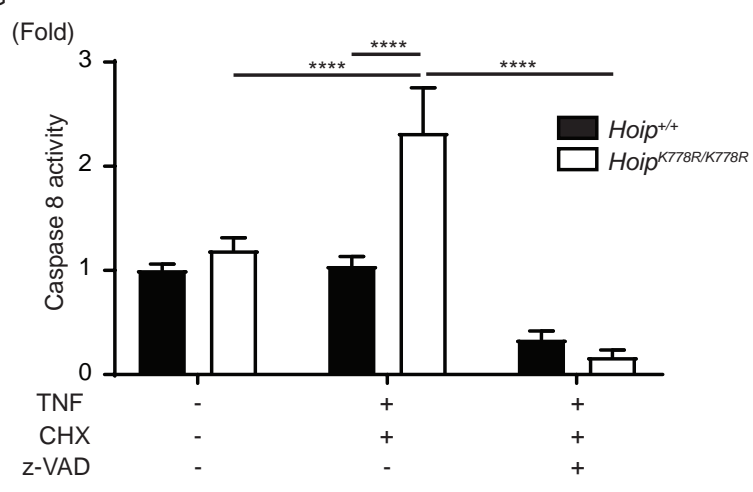

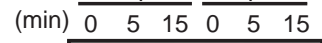

(kDa) 37

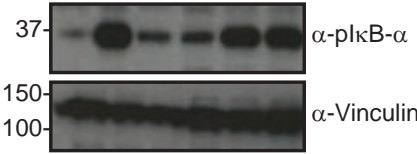

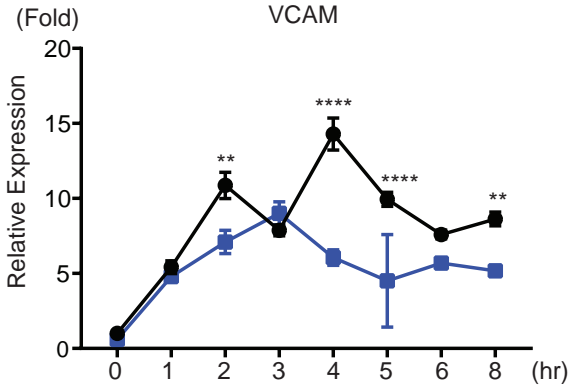

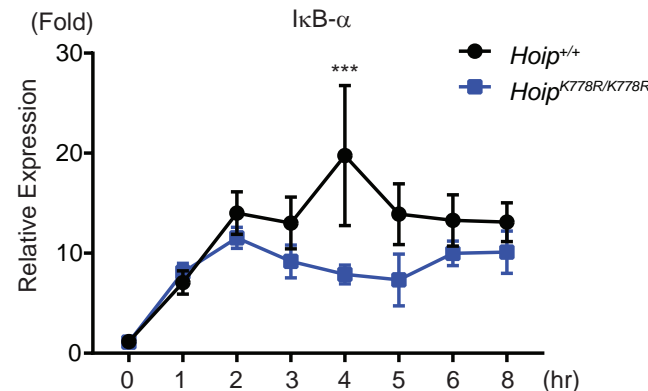

F

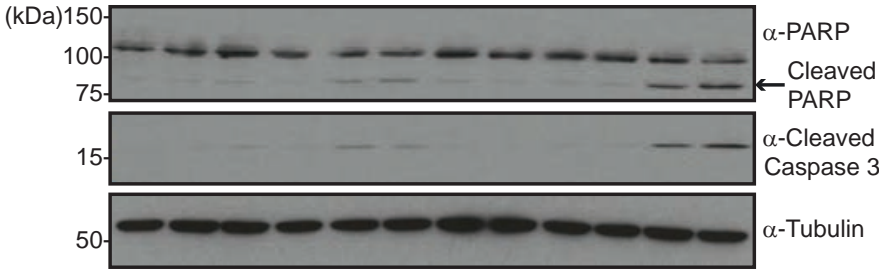

$\mathrm{H}$

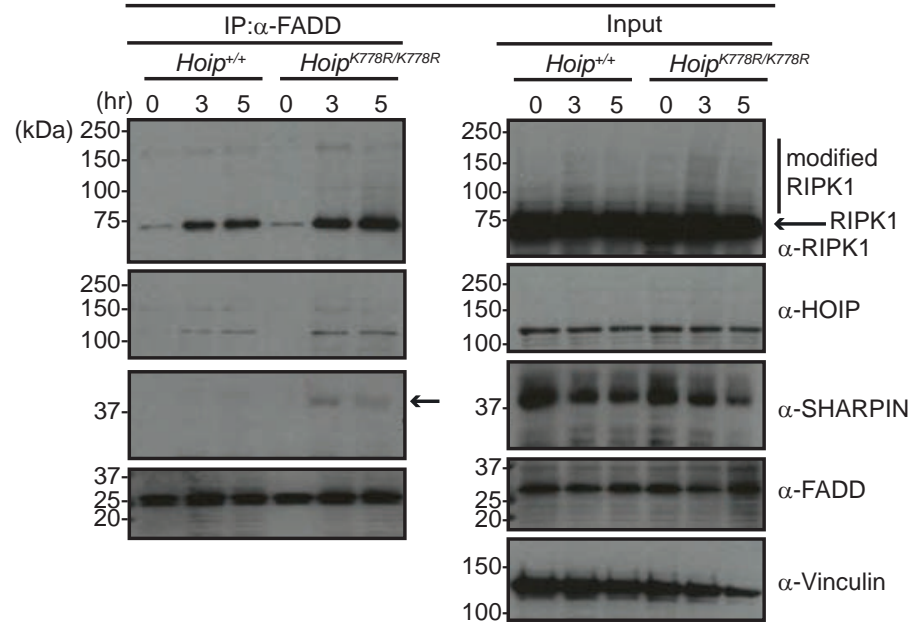


bioRxiv preprint doi: https://doi org/101101/742544; this version posted August 21, 2019. The copyright holder for this preprint (which was not certified by peer review) is the author/funder, who has granted bioRxiv a license to display the preprint in perpetuity. It is made $\mathrm{Hoip}^{+/+}$ avaitableremder aCC-BY-NC-ND 4.Aolipterpatienal license.

\begin{tabular}{|c|c|c|c|c|c|c|c|c|c|c|}
\hline \multirow[b]{2}{*}{ Sharpin } & & & & \multirow[b]{2}{*}{ Total } \\
\hline & $+/+$ & $+/ c p d m$ & $d m / c p d m$ & $+/+$ & $+/ c p d m$ & cpdm/cpdm & $+/+$ & $+/ c p d m$ & cpdm/cpdm & \\
\hline $\begin{array}{l}\text { weaned } \\
\text { (expected) }\end{array}$ & $\begin{array}{c}10 \\
(8.3)\end{array}$ & $\begin{array}{c}26 \\
(16.6)\end{array}$ & $\begin{array}{c}10 \\
(8.3)\end{array}$ & $\begin{array}{c}12 \\
(16.6)\end{array}$ & $\begin{array}{c}39 \\
(33.25)\end{array}$ & $\begin{array}{c}20 \\
(16.6)\end{array}$ & $\begin{array}{c}3 \\
(8.3)\end{array}$ & $\begin{array}{c}13 \\
(16.6)\end{array}$ & $\begin{array}{c}0 \\
(8.3)\end{array}$ & 133 \\
\hline
\end{tabular}

\begin{tabular}{c|ccc|c} 
& \multicolumn{3}{c}{ Hoip $^{K 778 R / K 778 R}$} & \\
\cline { 2 - 4 } Sharpin & $+/+$ & $+/ c p d m$ & $c p d m / c p d m$ & Total \\
\hline $\begin{array}{c}\text { E12.5 } \\
\text { (expected) }\end{array}$ & $\begin{array}{c}7 \\
(6.25)\end{array}$ & $\begin{array}{c}11 \\
(12.5)\end{array}$ & $\begin{array}{c}7 \\
(6.25)\end{array}$ & 25 \\
\hline $\begin{array}{c}\text { E13.5 } \\
\text { (expected) }\end{array}$ & $\begin{array}{c}5 \\
(5)\end{array}$ & $\begin{array}{c}10 \\
(10)\end{array}$ & $\begin{array}{c}5 \\
(5)\end{array}$ & 20 \\
\end{tabular}

Sharpin ${ }^{\text {cpdm/cpdm; }}$ Sharpin ${ }^{\text {cpdm/cpdm; }} ;$ Sharpin ${ }^{\text {cpdm/cpdm; }}$; $\operatorname{Tnfr}^{+/-}$
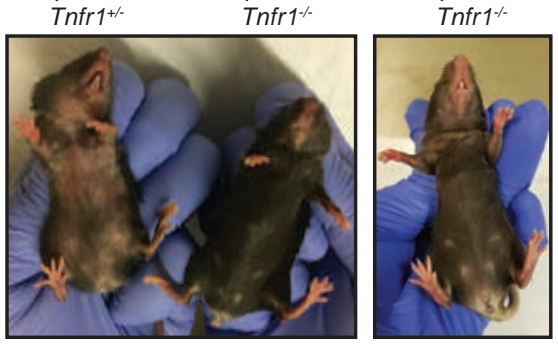

C

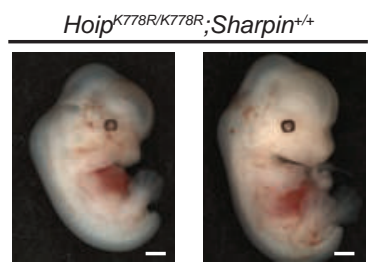

Hoip ${ }^{K 778 R / K 778 R ; S h a r p i n ~}{ }^{\text {cpdm/cpdm }}$

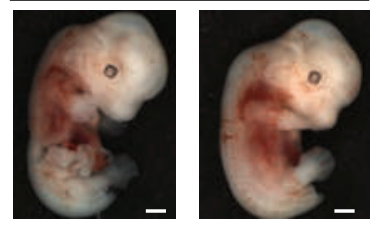

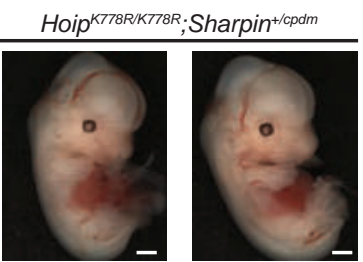

E

\begin{tabular}{|c|c|c|c|c|c|c|}
\hline \multicolumn{3}{|c|}{ 4-week old } & \multicolumn{4}{|c|}{ 8-week old } \\
\hline $\begin{array}{l}\text { Hoip }^{+/+} ; \\
\text {Sharpin }^{+/+}\end{array}$ & $\begin{array}{c}\text { Hoip }^{+/+} ; \\
\text {Sharpin } \\
\text { cpdm/cpdm; }\end{array}$ & $\begin{array}{c}\text { Hoip }^{+/ K 778 R} ; \\
\text { Sharpin } \\
\text { cpdm/cpdm; }\end{array}$ & $\begin{array}{l}\text { Hoip }^{+/+} ; \\
\text {Sharpin } \\
\text { Tnfr/ }{ }^{-1}\end{array}$ & $\begin{array}{l}\text { Hoip } \\
\text { Sharpinin } \\
\text { Shat/-; }\end{array}$ & $\begin{array}{c}\text { Hoip }^{+/ K 778 R} ; \\
\text { Sharpin } \\
\text { cpdm/cpdm; }\end{array}$ & $\begin{array}{l}\text { Hoip }{ }^{K 778 R / K 778 R} \\
\text { Sharpin }^{\text {cpdm/cpdm; }}\end{array}$ \\
\hline
\end{tabular}

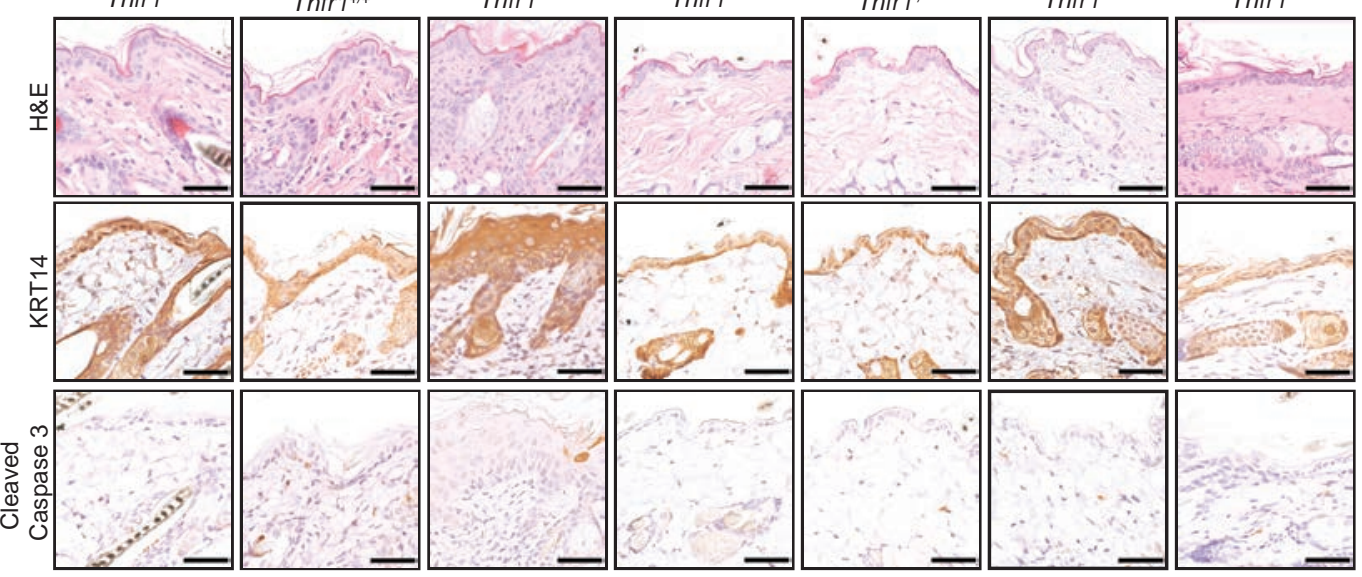


Figure 5 A
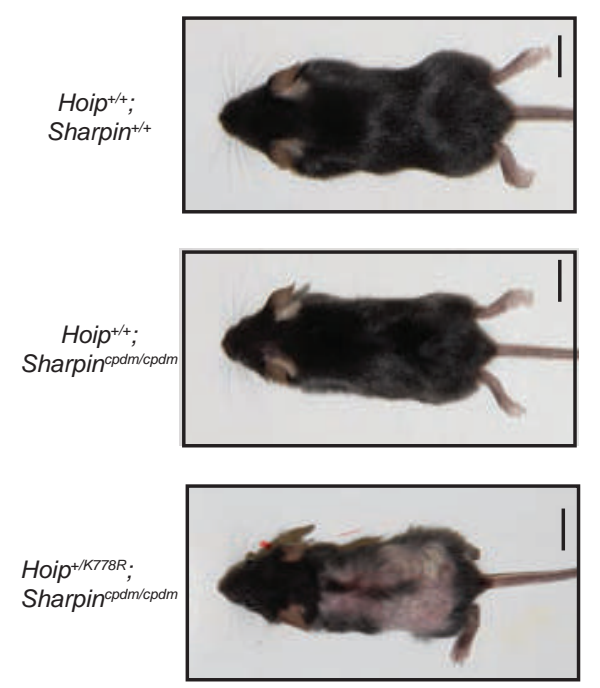

$\mathrm{C}$

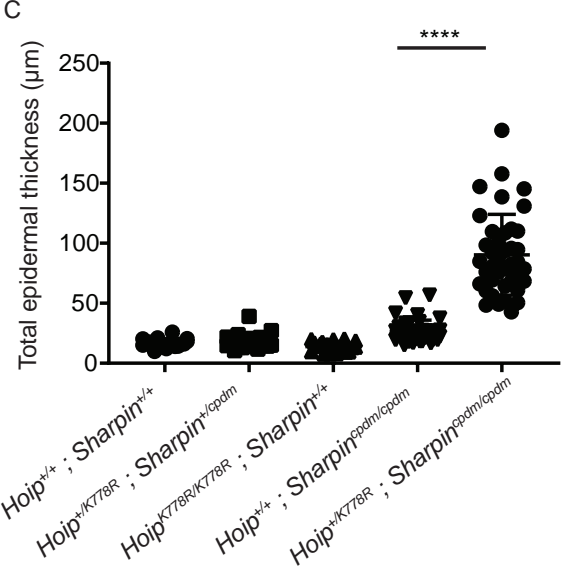

F

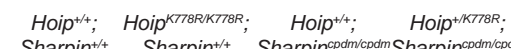

Sharpin $^{+++}$Sharpin ${ }^{\text {t+ }}$ Sharpin ${ }^{\text {codmcopdm }}$ Sharpin $^{\text {cod }}$

$\begin{array}{lllllllllllll}(\min ) & 0 & 5 & 15 & 0 & 5 & 15 & 0 & 5 & 15 & 0 & 5 & 15\end{array}$

hTNF - + + + + + + - +

(kDa) $37-0-0-0-00$
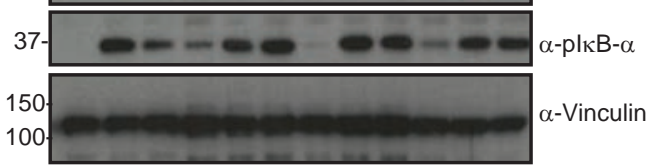

$\mathrm{H}$

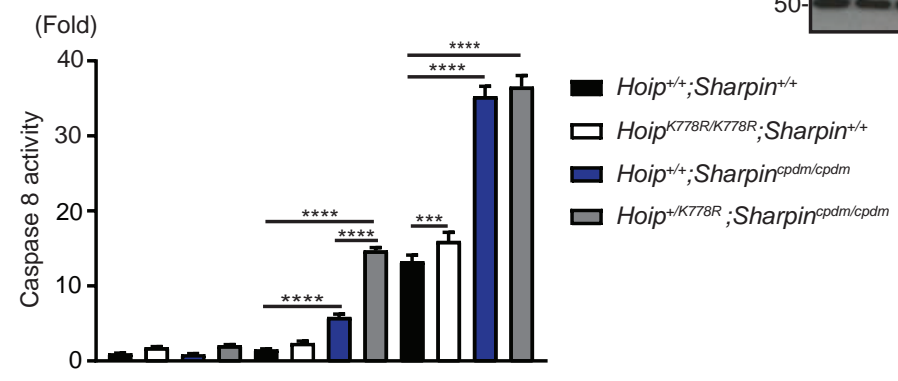

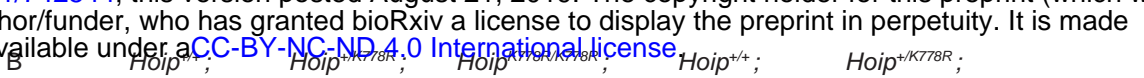

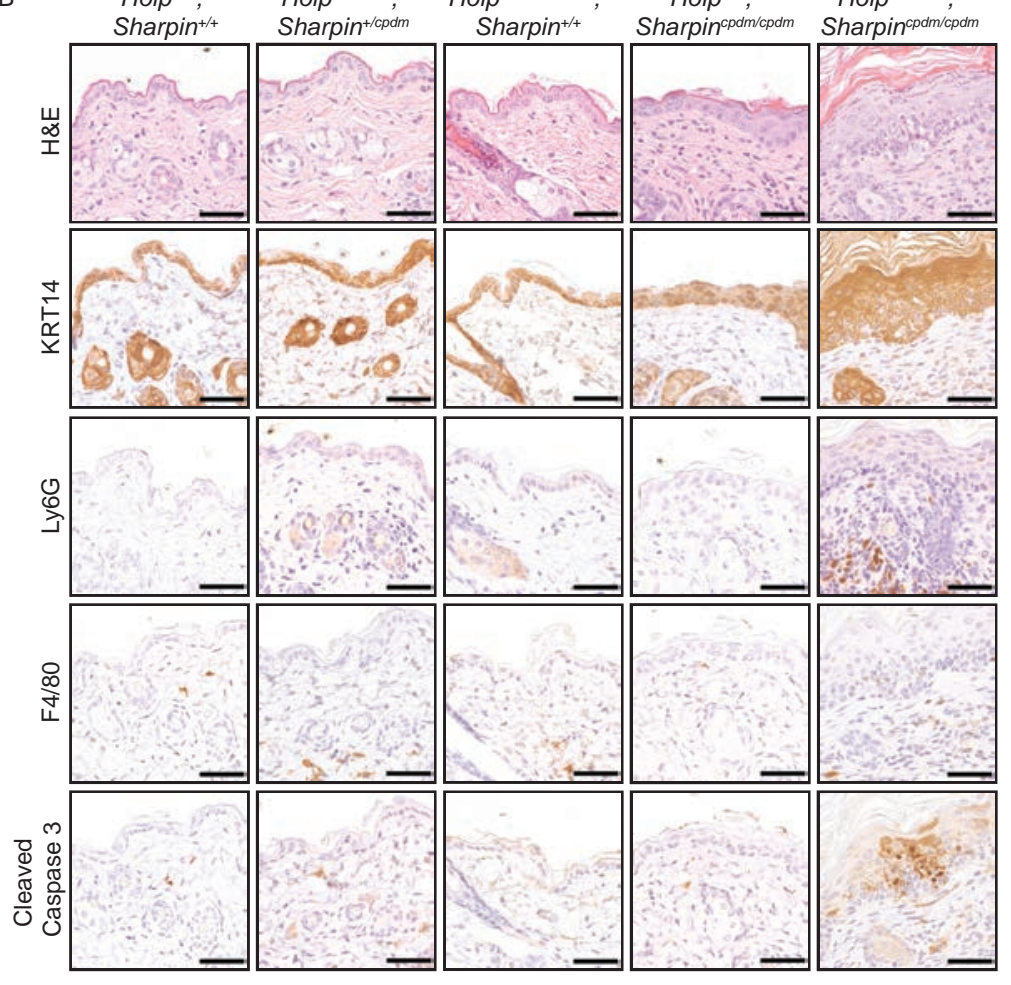

D

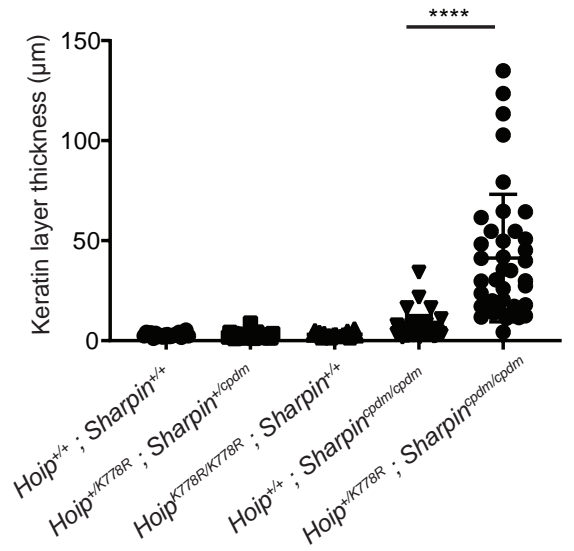

G

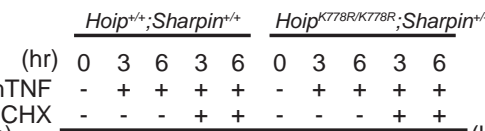

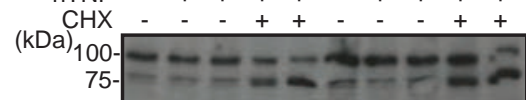

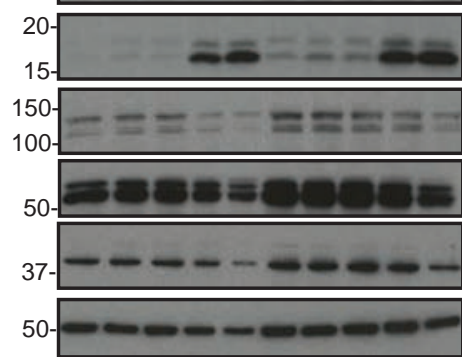

$\alpha$-Vinculin

*non-specific

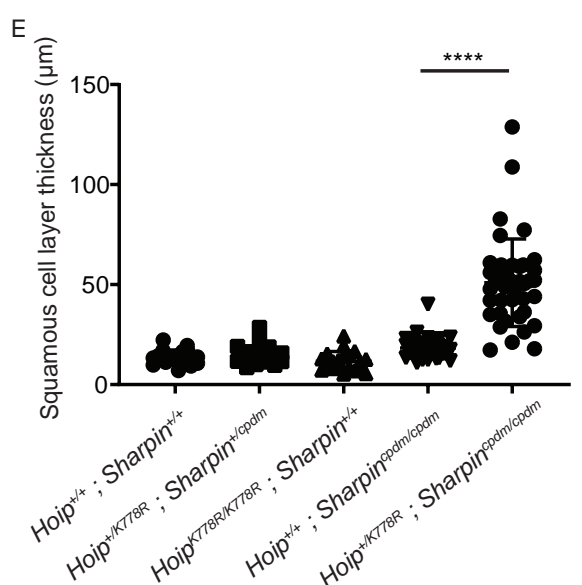

(hr)

0

$\mathrm{CHX}$ 
Figure 6 bioRxiv preprint doi: https://doi.org/10.1101/742544; this version posted August 21, 2019. The copyright holder for this preprint (which was not certified by peer review) is the author/funder, who has granted bioRxiv a license to display the preprint in perpetuity. It is made

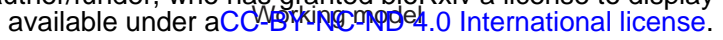
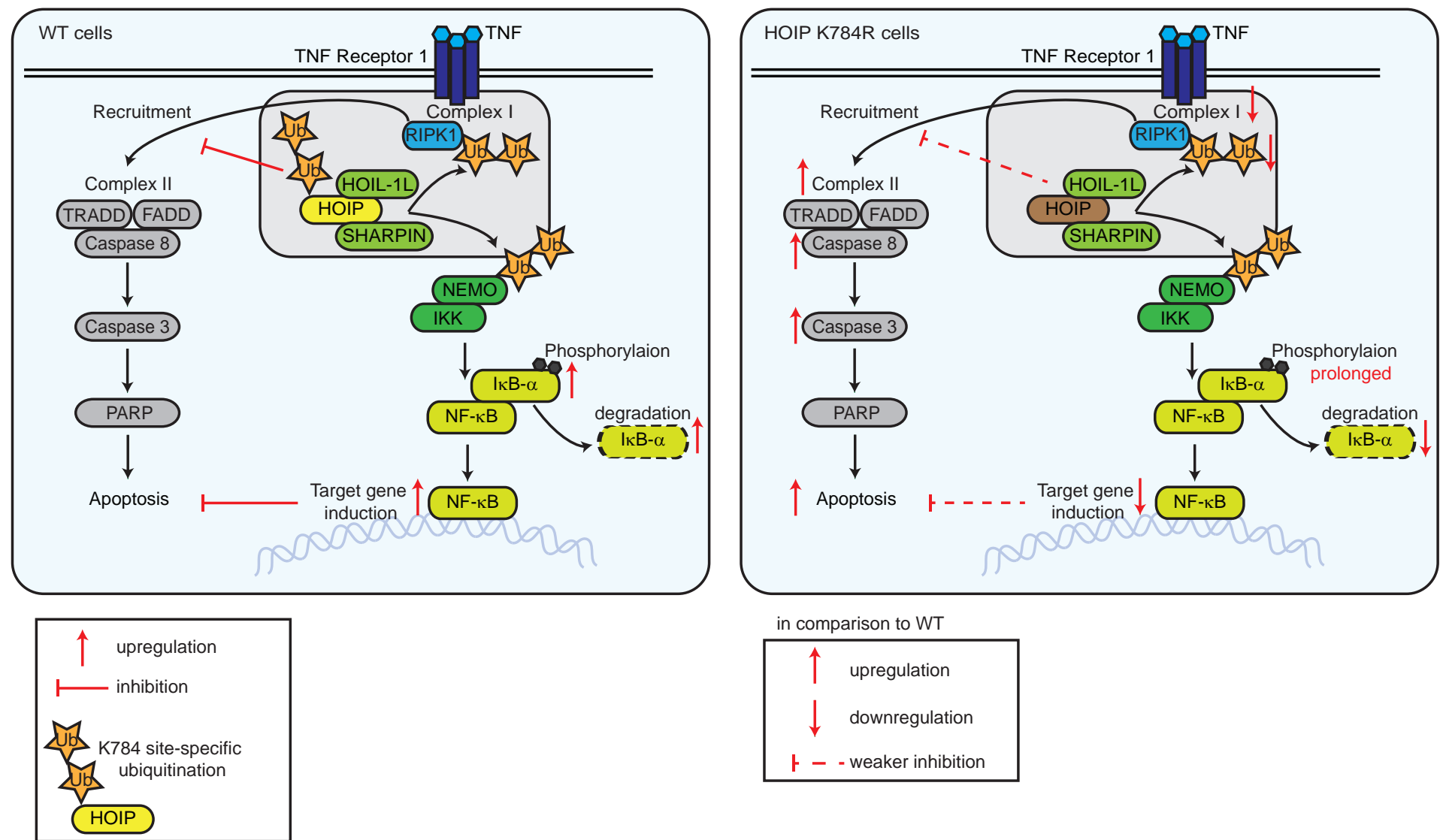
Supplementary information

\section{Site-specific ubiquitination of the E3 ligase HOIP regulates cell death and immune signaling}

Lilian M. Fennell, Luiza Deszcz, Alexander Schleiffer, Karl Mechtler, Anoop Kavirayani, Fumiyo Ikeda 
Supplementahiø/gxiæ preprint doi: https://doi.org/10.1101/742544; this version posted August 21, 2019. The copyright holder for this preprint (which was

A not certified by peer review) is the author/funder, who has granted bioBxiv a dicense to display
GST availablapwhiter aCC-BY-NC-ND 4.0 International license
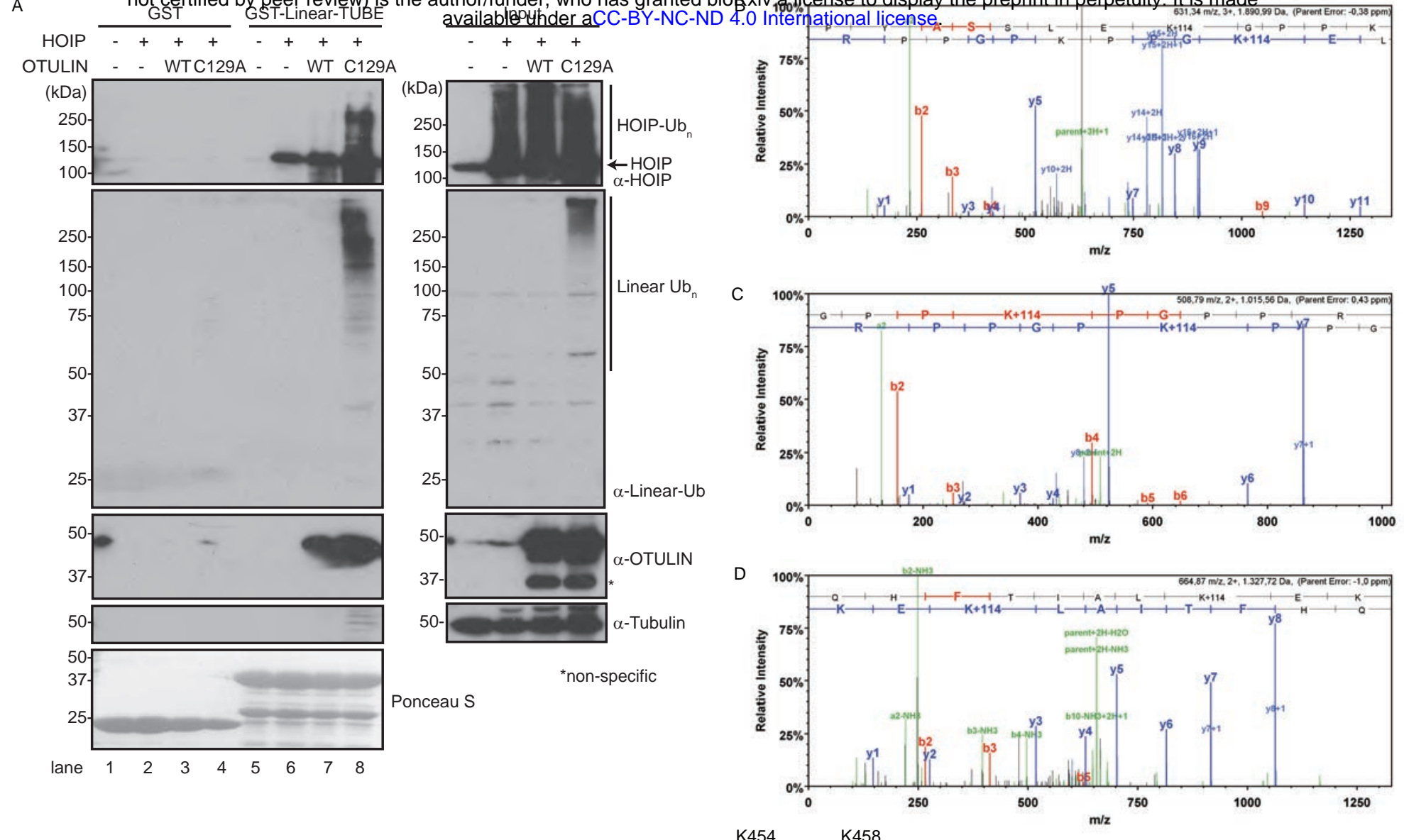

H. sapiens 413 WYCIHCTFCNSSPGWVCVMCNRTSSPIPAQHAPRPYASSLEKGPP - - - - KPGPPRRL - - SAPLPSSCGDPEKQRQDKMREEGL 489 C. lupus $\quad 420$ WYCIHCTFCNSGPGWVAMCNRTSS ILVQQAPQLHASSLEERLP - - - - EPRPPRCL - - SAPLPGYCGDPEKQRQDKMREEGL 496 M. musculus 407 WYCDHCTFCNSGPVWVCAMCNRTRD I PTQPALQSYPSSLEKGRP - - - - KPGSSQHL - - GSSLPASCGD EKQRQDKMRKEGL 483

M. domestica 410 WHCVHCTFRNSGP GWVCTMCNRTSSPTPPL-LPSWIPNSLGEGARTSVCLKPVSAHQISTPSASLHALRGDLEQQRQDKMREDGL 493

X. laevis 408 WQCSHCTFFNTQNGRVCEICDRTREGTA- $\ldots$

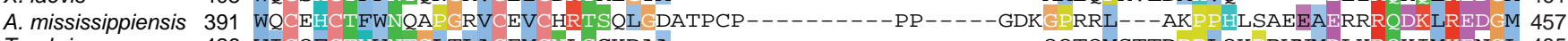

T. rubripes 426 WICQFCTYVNTGLTLACEMCNLSCKDAA - $\ldots$

$\mathrm{F}$

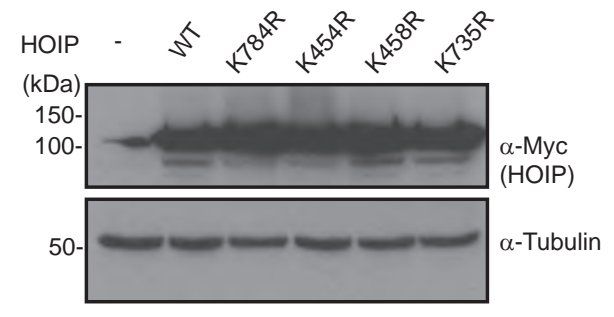

G

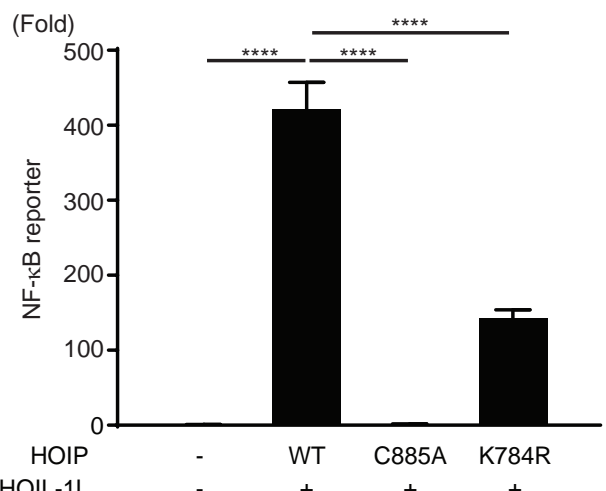

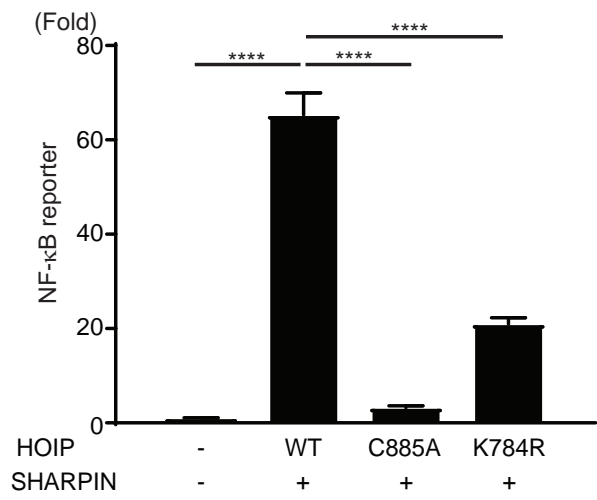


SupplementarygRxiy preprint doi: https://doi.org/10.1101/742544; this version posted August 21, 2019. The copyright holder for this preprint (which was te certified by peer review) is the author/funder, who has granted bioRxiv a license to display the preprint in perpetuity. It is made available under aCC-BY-NC-ND 4.0 International license.

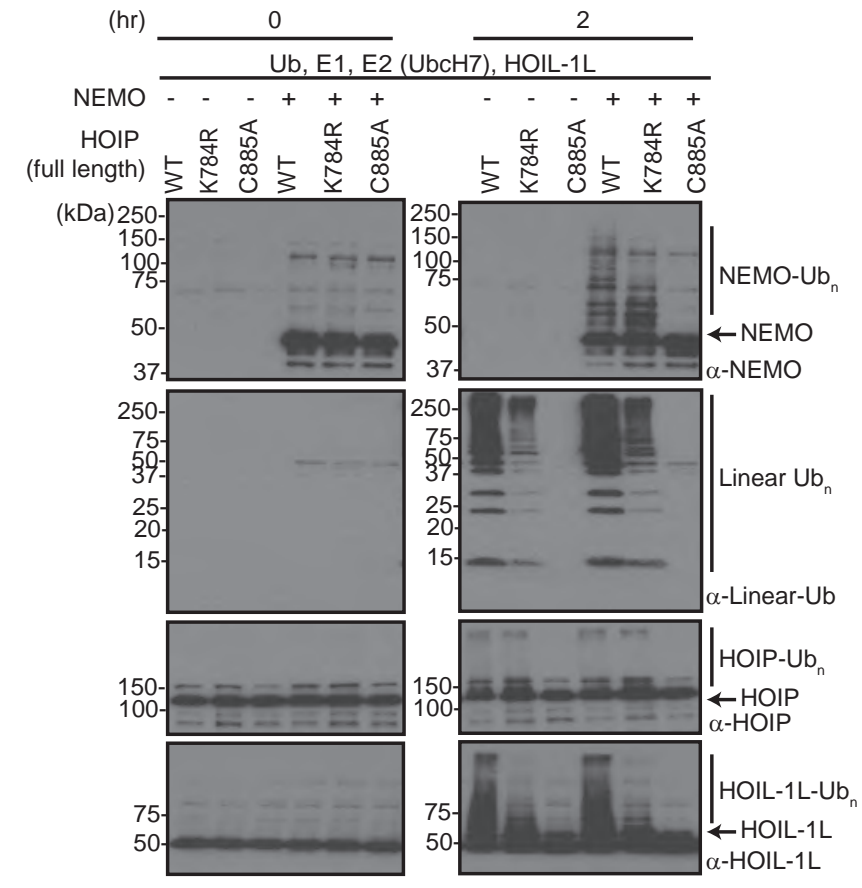


Supplementdbjafigaivepseprint doi: https://doi.org/10.1101/742544; this version posted August 21,2019 . The copyright holder for this preprint (which was A not certified by peer review) is the author/funder, who has granted bioRxiv a license to display the preprint in perpetuity. It is made

gRNA

Cas9 mRNA Donor oligonucleotide
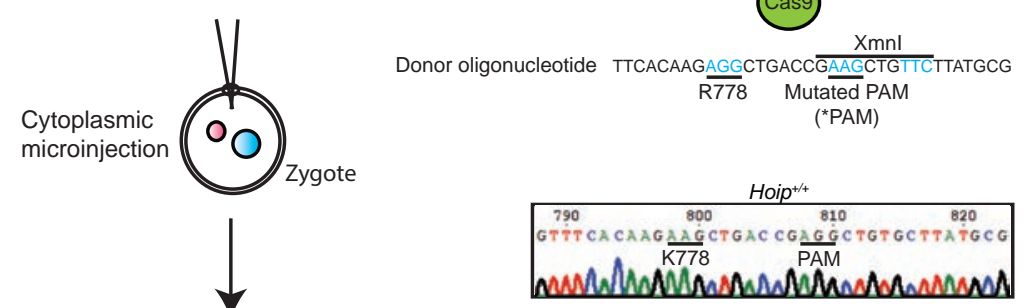

Wildtype $\frac{\text { Target (18nt) }}{\text { TTCACAAGAGCTGACCGAGGCTGTGCTTATGCG }}$

$$
\begin{gathered}
\text { R778 Mutated PAM } \\
\left({ }^{*}\right. \text { PAM) }
\end{gathered}
$$

Donor oligonucleotide TTCACAAGAGGCTGACCGAAGCTGTTCTTATGCG

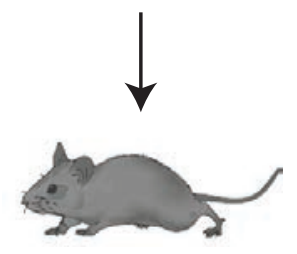

C

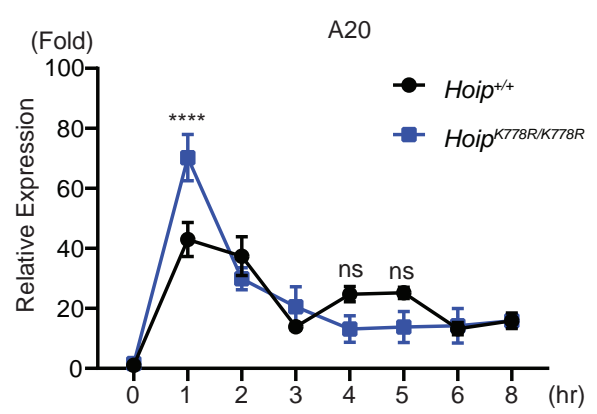

D (Fold)

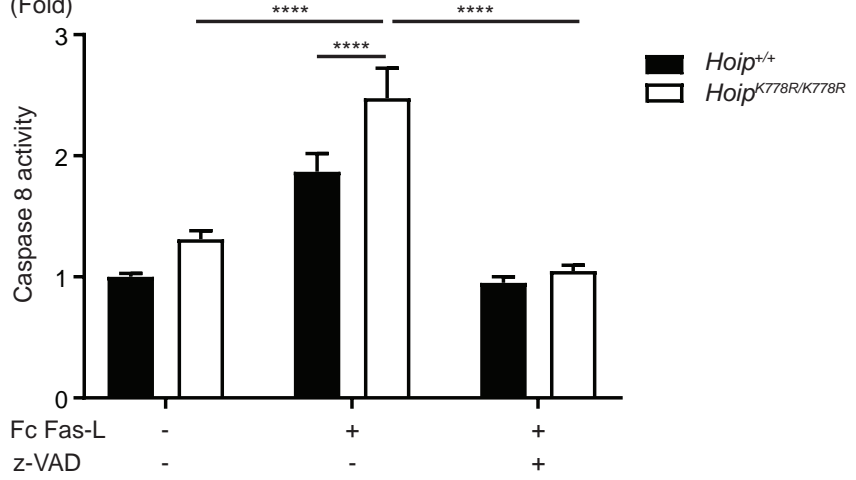

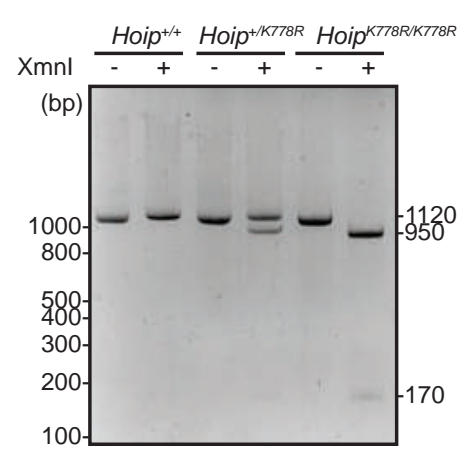

780
GTTTCACAAGAGGCTGACCGAAGCTGTTCTTATGCG
R778
RAM

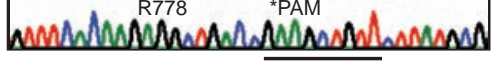


bioRxiv preprint doi: https://doi.org/10.1101/742544; this version posted August 21, 2019. The copyright holder for this preprint (which was

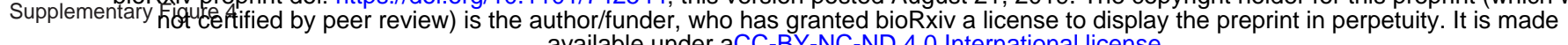
A Hoip $^{\text {K778R/K778R; }}$ Sharpin ${ }^{+/+}$

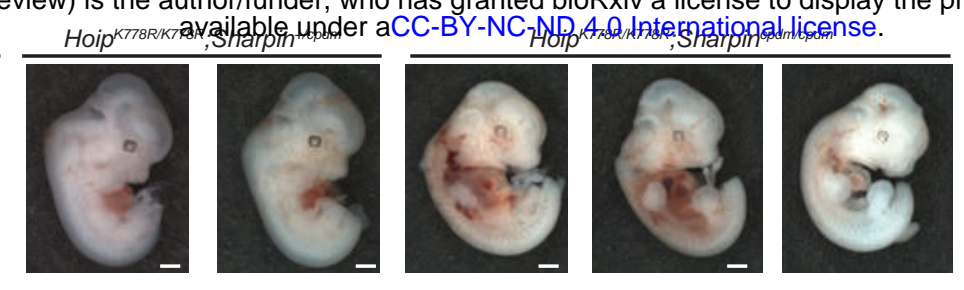

B

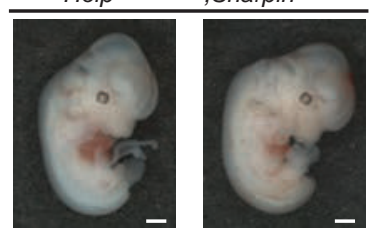

4-week old

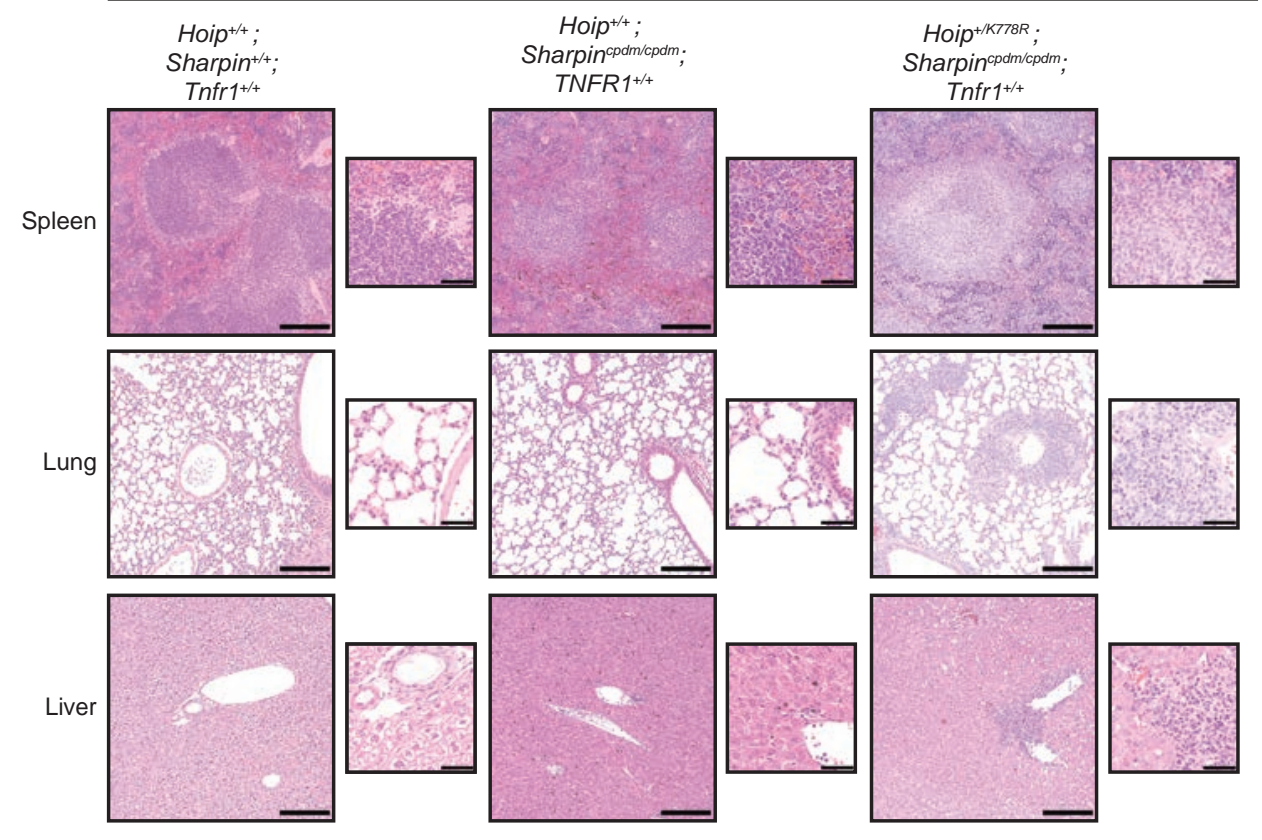

8-week old

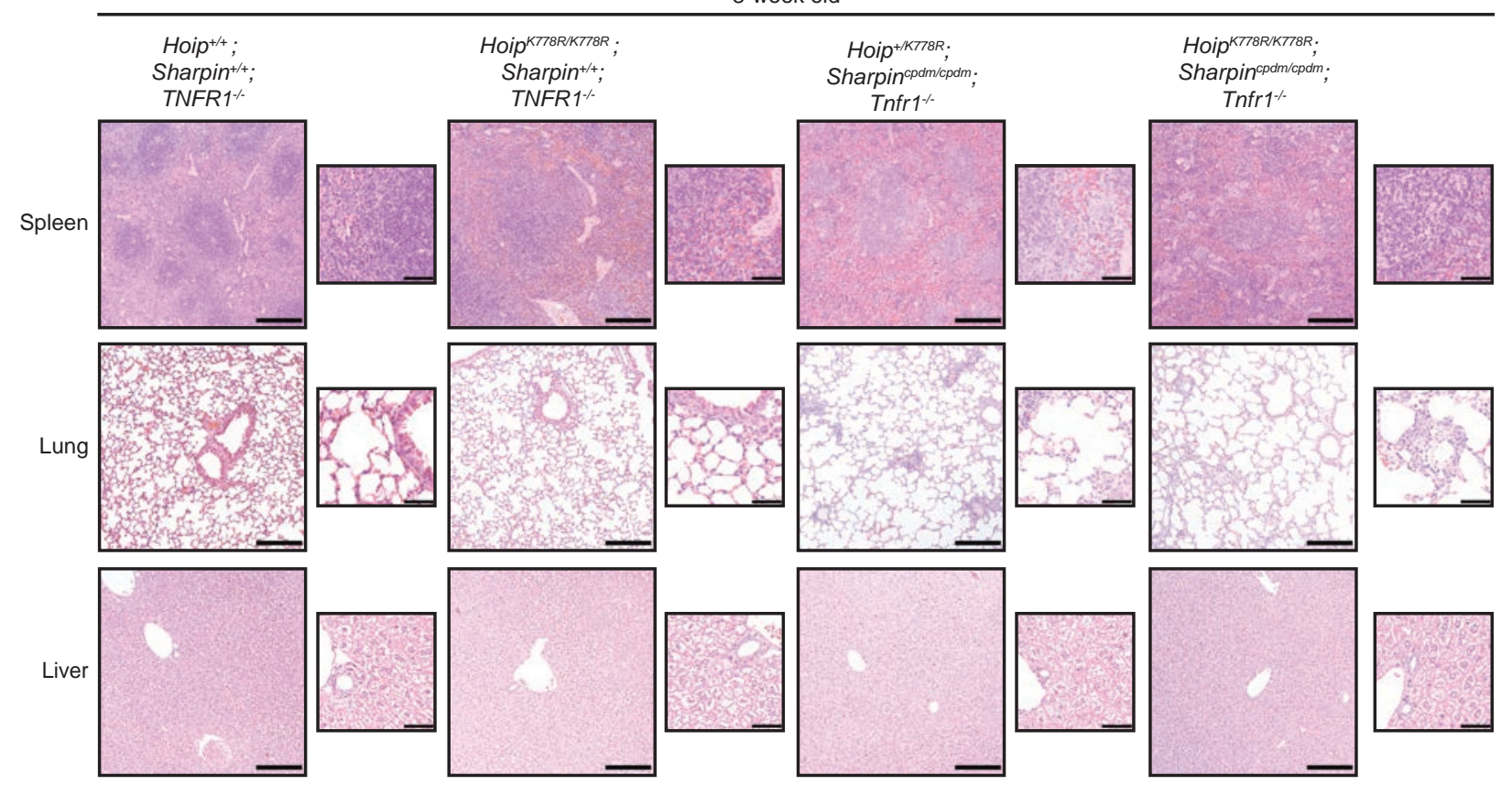


SupplementarbipiBuxid wreprint doi: https://doi.org/10.1101/742544; this version posted August 21, 2019. The copyright holder for this preprint (which was not certified by peer review) is the author/funder, who has granted bioRxiv a license to display the preprint in perpetuity. It is made

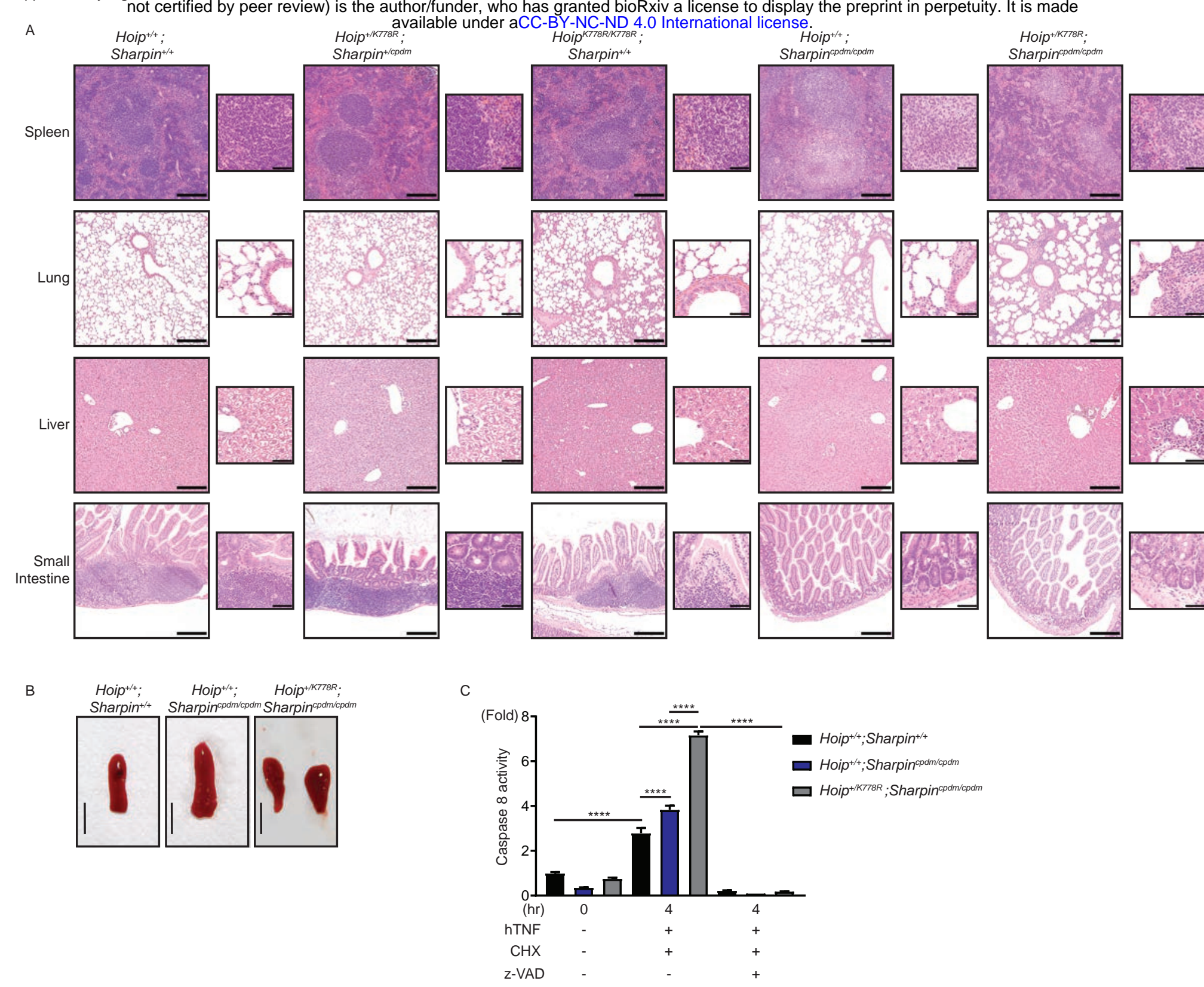




\section{Supplementary figure legends}

\section{Supplementary Figure 1 - HOIP is ubiquitinated in cells.}

A. Immunoblotting of ubiquitinated HOIP enriched by Linear-TUBE pulldown assays in total cell extracts from HEK293T cells transiently expressing Myc-HOIP, Myc-OTULIN wildtype (WT) or a catalytically inactive mutant (C129A). Linear ubiquitin chains and ubiquitination of HOIP were detected by immunoblotting. Representative data shown from three independent experiments.

B-D. Mass spectrometry spectra corresponding to a peptide containing HOIP-K454, K458 and K735 with double Gly (114+K).

E. Multiple sequence alignment of HOIP orthologues of the indicated species illustrating the position of K454 and K458 in HOIP according to the ClustalX color scheme.

F. Expression of Myc-HOIP mutants of the identified ubiquitination sites (K784, K454, K458, K735) examined by immunoblotting. Total cell extracts of HEK293T cells transiently expressing Myc-HOIP WT or mutants subjected to SDS-PAGE followed by immunoblotting using the indicated antibodies. An anti-Tubulin antibody used for loading control.

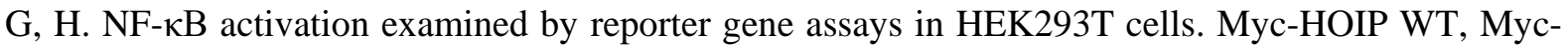
HOIP C885A or Myc-HOIP K784R were expressed in HEK293T cells with HOIL-1L-HA or FLAGSHARPIN with reporter plasmids. Luciferase signal was normalized by internal control, Renilla signals. Representative data shown from three independent experiments, $n=4$, data presented as mean $\pm S D$, $* * * * \mathrm{p} \leq 0.001$ by ANOVA.

\section{Supplementary Figure 2 - Recombinant HOIP K784R protein catalyzes linear ubiquitin chains} in vitro.

A. Immunoblotting of in vitro ubiquitination assay samples using recombinant proteins of ubiquitin, E1, E2 (UbcH7), E3 (LUBAC components, HOIP and HOIL-1L without SHARPIN) and a known substrate NEMO. HOIP wildtype (WT), K784R or C885A mutants were used as indicated. Unanchored linear ubiquitin chain formation, ubiquitination of NEMO, HOIP and HOIL-1L were detected by immunoblotting using the indicated antibodies. Representative data shown from three independent experiments.

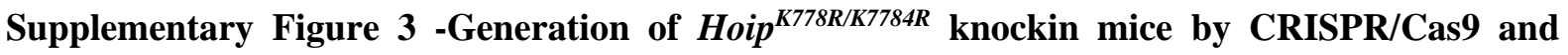 cellular responses.}

A. A schematic illustrating the strategy to generate Hoip $^{K 778 R / K 7784 R}$ knockin mice. Guide RNA (gRNA), Cas9 mRNA, and donor single-stranded oligonucleotide were microinjected into the cytosol of zygotes. Mouse HOIP K778 (equivalent to human HOIP K784) was mutated to Arg (R778), a silent mutation 
for an Xmn1 restriction site was introduced for genotyping, as well as for the PAM sequence. Sanger sequencing results of the corresponding target region are shown.

B. Genotyping of $\mathrm{Hoip}^{+/+}$, Hoip ${ }^{+/ K 778 R}$ and Hoip ${ }^{K 778 R / K 778 R}$ mice. Restriction Fragment Length Polymorphism (RFLP) analysis of a PCR product (1120bp) of genomic DNA isolated from Hoip ${ }^{K 778 R}$ offspring using Xmn1. Hoip ${ }^{+/+}$: undigested, Hoip ${ }^{+/ K 778 R}$ : one allele digested, Hoip ${ }^{K 778 R / K 778 R}$ : both allege digested.

C. Induction of TNF-dependent NF- $\mathrm{B}$ target genes, A20 in immortalized MEFs $\left(\right.$ Hoip $^{+/+}$and Hoip ${ }^{K 778 R / K 778 R}$ ) examined by qRT-PCR. RNA extracted from MEFs treated with hTNF (20ng/ml) for the indicated time followed by RT, subjected to qPCR. Signals were normalized to $\beta$-actin. Representative data shown from three independent experiments $(n=3)$.

D. Caspase 8 activity in FasL-treated Hoip $^{+/+}$and Hoip ${ }^{K 778 R / K 778 R}$ MEFs. A luminol-based Caspase 8 assay data using MEFs treated by Fc-FasL (200ng/ml) for two hours. A representative data shown from two independent experiment, $\mathrm{n}=4$.

Data presentation: mean $\pm \mathrm{SD}, * * * * \mathrm{p} \leq 0.001$ by ANOVA.

Supplementary Figure 4 - Grossly abnormal Hoip ${ }^{K 778 R / K 778 R}$;Sharpin ${ }^{\text {cpdm/cpdm }}$ embryos and mitigation of systemic inflammation in $\mathrm{Hoip}^{\mathrm{K} 778 R / \mathrm{K} 778 R}$; Sharpin ${ }^{\text {cpdm/cpdm }}$ by TNFR1 knockout

A. Gross images of Hoip ${ }^{K 778 R / K 778 R}$;Sharpin ${ }^{+/+}, \quad$ Hoip $^{\text {K778R/K778R }}$;Sharpin ${ }^{+/ \text {cpdm }}$ and Hoip $^{\text {K778R/K778R }}$;Sharpin ${ }^{\text {cpdm/cpdm }}$ embryos at E12.5. Scale bars :1mm

B. H\&E staining of spleen, lung and liver sections from mice of the indicated genotypes. Scale bars: $200 \mu \mathrm{m}$ and $50 \mu \mathrm{m}$ (higher magnification images).

Supplementary Figure 5 - Hoip $^{+/ K 778 R}$; Sharpin ${ }^{\text {cpdm/cpdm }}$ mice show multi-organ inflammation.

A. H\&E staining of spleen, lung, liver and small intestine from mice of the indicated genotypes at four weeks of age. Scale bars: $200 \mu \mathrm{m}$ and $50 \mu \mathrm{m}$ (higher magnification images).

B. Macroscopic images of spleens from mice of the indicated genotypes at four weeks of age. Two representative spleens are shown for Hoip ${ }^{+/ K 778 R}$; Sharpin ${ }^{\text {cpdm/cpdm }}$ mice. Scale bars: $10 \mathrm{~mm}$.

C. TNF-induced Caspase 8 activity in primary ear-derived fibroblasts from mice of the indicated genotypes. Luminol-dependent activity of Caspase 8 in MEFs treated with hTNF (100ng/ml) with or without CHX $(1 \mu \mathrm{g} / \mathrm{ml})$ or $\mathrm{z}-\mathrm{VAD}(20 \mu \mathrm{M})$. Representative data from three independent experiments $(\mathrm{n}=4$, data presented as mean $\pm \mathrm{SD}, * * * * \mathrm{p} \leq 0.0001)$. 